"Protamine/DNA/niosome ternary non-viral vectors for gene delivery to the retina. The role of protamine" Puras, G., Martínez-Navarrete, G., Mashal, M., Zarate, J., Agirre, M., Ojeda, E., Grijalvo, S., Eritja, R., Díaz-Tahoces, A., Avilés-Trigueros, M., Fernandez, E., Pedraz, J.L. Mol. Pharm., 12(10), 3658-3671 (2015). doi: 10.1021/acs.molpharmaceut.5b00422

\title{
Protamine/DNA/Niosome Ternary Nonviral Vectors for Gene Delivery to the Retina: The Role of Protamine
}

\author{
G. Puras, ${ }^{1,2,+}$ G. Martínez-Navarrete,${ }^{2,3,+}$ M. Mashal, ${ }^{1}$ J. Zarate, ${ }^{1,2}$ M. \\ Agirre, ${ }^{1,2}$ E. Ojeda, ${ }^{1,2}$ S. Grijalvo, ${ }^{2,4}$ R. Eritja, ${ }^{2,4}$ A. Díaz-Tahoces, ${ }^{2,3}$ M. \\ Avilés-Trigueros, ${ }^{5}$ E. Fernández, ${ }^{2,3}$ J.L. Pedraz ${ }^{*}, 1,2$ \\ ${ }^{1}$ NanoBioCel Group and ${ }^{2}$ Biomedical Research Networking Center in Bioengineering, \\ Biomaterials, and Nanomedicine (CIBER-BBN), University of the Basque Country \\ (UPV/EHU), Paseo de la Universidad 7, 01006 Vitoria-Gasteiz, Spain \\ ${ }^{3}$ Neuroprothesis and Neuroengineering Research Group, Miguel Hernández University, \\ 03202 Alicante, Spain. \\ ${ }^{4}$ Institute for Advanced Chemistry of Catalonia, IQAC-CSIC, Spanish Council for \\ Scientific Research, 08034 Barcelona, Spain \\ ${ }^{5}$ Laboratory of Experimental Ophthalmology, Faculty of Medicine, University of Murcia, \\ Regional Campus of International Excellence "Campus Mare Nostrum", E-30100 \\ Murcia, Spain
}

${ }^{+}$These authors contributed equally to this work.

\section{ABSTRACT.}

The present study aimed to evaluate the incorporation of protamine into niosome/DNA vectors to analyze the potential application of this novel ternary formulation to deliver the pCMS-EGFP plasmid into the rat retina. Binary vectors based on niosome/DNA and ternary vectors based on protamine/DNA/niosomes were prepared and physicochemically characterized. In vitro experiments were performed in ARPE-19 cells. At 1:1:5 protamine/DNA/niosome mass ratio, the resulted ternary vectors had $150 \mathrm{~nm}$ size, positive charge, spherical morphology, and condensed, released, and protected the DNA against enzymatic digestion. The presence of protamine in the ternary vectors improved transfection efficiency, cell viability, and DNA condensation. After ocular administration, the EGFP expression was detected in different cell layers of the retina depending on the administration route without any sign of toxicity associated with the formulations. While subretinal administration transfected mainly photoreceptors and retinal pigment epithelial cells at the site of injection, intravitreal administration produced a more uniform distribution of the protein expression through the inner layers of the retina. The protein expression in the retina persisted for at least one month after both administrations. Our study highlights the flattering properties of protamine/DNA/niosome ternary vectors for efficient and safe gene delivery to the rat retina.

Keywords: niosomes, protamine, gene therapy, retina, nonviral vectors, nanotechnology 


\section{INTRODUCTION}

Gene therapy represents a promising therapeutic approach to correct genetic deficiencies or to treat acquired diseases. ${ }^{1}$ The success of the therapy relies on the design of efficient delivery systems to introduce exogenous genetic materials into the target cells. ${ }^{2}$ Nevertheless, gene replacement therapy is still far to be considered as a mainstream medicine option. Besides safety concerns, other relevant limitations such as the poor uptake of gene delivery vectors and the posterior gene expression, along with the attenuated expression of the gene over time, clearly jeopardize the clinical application. Therefore, many strategies are being explored by the research community to circumvent these issues. ${ }^{3}$

Among the human organs, the eye has unique advantages for gene therapy purposes. In particular, its small size, immune privileged location, and well-defined compartmentalized anatomy enable local vector delivery of small volumes with low likelihood of systemic dissemination, minimizing the potential adverse reactions that may follow after intraocular injection of foreign antigens. ${ }^{4}$ Furthermore, since the media is transparent, the gene transfer process can be easily tracked through noninvasive techniques, and minor changes of visual function can be monitored by sensitive methods. ${ }^{5}$ Finally, most of the inherited diseases that cause irreversible blindness such as Retinitis Pigmentosa, Stargardt's disease, Choroideremia, and Age-related Macular Degeneration are well localized mainly on retinal ganglion cells, photoreceptors, or retinal pigment epithelium6 and have a well-known genetic background. Despite these relevant advantages, few effective treatments are available at present for the treatment of inherited retinal diseases, and many of the affected patients must live under impaired vision, even with the best medical option. Therefore, research on retinal gene therapy offers hope and represents a logical and promising approach to develop new safe and effective gene based treatments to translate animal research into clinical trials. ${ }^{6,7}$

Actually, retinal gene delivery systems can be classified in two main groups: viral and nonviral vectors. Even if engineered to minimize adverse biological effects, viral vectors may induce inflammation, immunogenicity, and secondary oncogenesis due to insertional mutagenesis. ${ }^{8,9}$ These handicaps, along with the limited DNA carrying apacity, the high cost of production, and the negative public perception of viral vectors, ${ }^{10-12}$ have prompted the need to develop safer and biologically inactive nonviral strategies. ${ }^{13}$ Among nonviral vectors, cationic lipid/ DNA complexes (lipoplexes) have shown tangible successes in retinal gene delivery applications. ${ }^{14-17}$

Recently, we elaborated novel niosomes based on the 2,3- di(tetradecyloxy)propan-1amine cationic lipid, combined with squalene and polysorbate 80 , to transfect efficiently the rat retina with the pCMS-EGFP reporter plasmid. ${ }^{18}$ In a logical effort to progress and develop novel safe and efficient nonviral retinal gene delivery vectors, we have incorporated in the present study protamine to our niosome formulation to obtain protamine/DNA/niosome ternary vectors. Protamine is a peptide obtained from the sperm of salmon or herring with excellent properties for gene delivery purposes since it condenses DNA, and its rich sequences in arginine promote active nuclear transport. ${ }^{19}$ Additionally, protamine is a FDAapproved compound with a documented safety profile. However, it has been reported in the literature that protamine/ DNA vectors by themselves do not yield high levels of transfection efficiency ${ }^{20,21}$ probably due to the high hydrophilicity of the protamine, which could hamper the entry through the cellular membrane. ${ }^{21}$ Therefore, protamine has been successfully incorporated mainly into lipid formulations such as liposome ${ }^{22,23}$ and in the past few years into solid lipid nanoparticles to increase transfection efficiency. ${ }^{24-26}$ Consequently, we have hypothesized that the incorporation of protamine to our niosome formulation, at an appropriate proportion, might lead to the design of novel nonviral ternary vectors, with a nontoxic profile, that could transfect efficiently cells of the rat retina after intravitreal and subretinal injection. A schematic diagram of the structure of both binary and ternary vectors with the chemical compounds involved in the noisome formulation is represented in Figure 1 of the Supporting Information. 
To validate our hypotehsis, we used the reporter pCMSEGFP plasmid to elaborate binary and ternary vectors based on niosome/DNA and protamine/DNA/niosomes complexes respectively at different mass ratios $(\mathrm{w} / \mathrm{w})$. The resulting vectors were characterized in terms of size, zeta potential, morphology, and the ability to condense, protect the DNA from enzymatic digestion, and release the protected DNA. This information was critical to determine the optimal ratios for transfection. In vitro experiments were performed in ARPE-19 cells to evaluate the transfection efficiency, viability, and intracellular DNA trafficking. Finally, the most promising formulation was administered by subretinal and intravitreal injections to evaluate any sign of toxicity or damage associated with the administration of the formulation by spectral domain optical coherence tomography (SD-OCT) as well as the expression of the enhanced green fluorescent protein (EGFP) by immunohistochemistry analysis in different cells and layers of the retina. According to our knowledge, this is the first time that the incorporation of protamine at an appropriate proportion into cationic niosomes has been evaluated for retinal gene delivery purposes.

\section{MATERIALS AND METHODS}

\subsection{Materials.}

The plasmid pCMS-EGFP, which encodes the EGFP, was propagated in Escherichia coli DH5- $\alpha$ and purified using the Qiagen endotoxin-free plasmid purification Maxi-prep kit (Qiagen, Santa Clarita, CA, USA) according to the manufacturer's instructions. Concentration of pDNA was quantified by measuring absorbance at $260 \mathrm{~nm}$ using a NanoDrop (ND-1000 Spectrophotometer, Thermo Fisher Scientific Inc. Denver, USA). The purity of the plasmid was verified by agarose gel electrophoresis in Tris Borate-EDTA buffer, pH 8.0 (TBE buffer). DNA bands were detected using GelRed (Biotium, Hayward, California, USA), and images were observed with a ChemiDoc MP Imaging System (Bio-Rad,

USA). DNase I, sodium dodecyl sulfate (SDS), squalene, protamine sulfate, and PBS were purchased from Sigma-Aldrich (Madrid, Spain); dichloromethane was purchased from Panreac (Barcelona, Spain). The labeling of plasmid pCMS-EGFP with fluorescein isothiocyanate (FITC) and ethidium monoazide (EMA) was carried out by DareBio S.L (Elche, Spain). Hoechst 33342, Fluoromont $\mathrm{G}$ was from SouthernBiotech (Coultek, Spain). Dulbecco's Modified Eagle's medium-Hanks Nutrient Mixture F-12, Opti-MEM reduced medium, fetal bovine serum, antibiotic/antimicotic solution, Lipofectamine 2000, and 0.05\% trypsin/EDTA were acquired from Invitrogen (San Diego, California, US). Polysorbate 80 (Tween 80 ) was provided by Vencaser (Bilbao, Spain). Retinal pigmented epithelial (ARPE-19) cells were obtained from the American Type Culture Collection (ATCC). The BD Viaprobe kit was provided by BD Biosciences (Belgium).

\subsection{Production of Cationic Niosomes and Preparation of Binary and Ternary Vectors.}

The cationic lipid 2,3- di(tetradecyloxy)propan-1-amine was synthesized by the experimental protocol described previously, ${ }^{27}$ and cationic niosomes based on the aforementioned lipid were elaborated by the solvent emulsification-evaporation technique. ${ }^{18}$ Niosome/DNA binary vectors were elaborated by mixing an appropriate volume of a pCMS-EGFP plasmid stock solution $(0.5 \mathrm{mg} / \mathrm{mL})$ with different volumes of the niosome suspension to obtain niosome/DNA binary vectors due to the electrostatic interactions between the incubated cationic niosomes and the negatively charged plasmid. The niosome/DNA ratio was expressed as the ratio of cationic lipid to DNA (w/w). Different niosome/DNA ratios were elaborated: 1:1, $2: 1,5: 1,10: 1,15: 1$, and 30:1. Protamine/DNA/niosome ternary vectors were prepared by first binding protamine to DNA at different ratios $(w / w)$. Briefly, an appropriate volume of a protamine solution $(0.5 \mathrm{mg} / \mathrm{mL})$ was vortexed for $30 \mathrm{~s}$ with different volumes of a pCMS-EGFP plasmid solution $(0.5 \mathrm{mg} / \mathrm{mL})$ to obtain different protamine/DNA ratios $(\mathrm{w} / \mathrm{w}): 0.25: 1,0.5: 1$, $1: 1,2: 1$, and $4: 1$. Complexes were incubated for $30 \mathrm{~min}$ at room temperature to enhance 
electrostatic interactions between the plasmid and the protamine. Thereafter, the protamine/DNA complexes were further mixed for $30 \mathrm{~min}$ with a suspension of the previously prepared niosomes, and electrostatic interactions between protamine/DNA complexes and niosomes led to the formation of the protamine/DNA/niosome ternary vectors. The proportion of each component was expressed as the protamine/ DNA/cationic lipid ratio (w/w/w).

\subsection{Physicochemical Characterization of Vectors.}

Both niosome/DNA binary vectors and protamine/DNA/ niosome ternary vectors were physicochemically characterized as described previously in terms of DNA condensation, DNA release upon the addition of SDS and DNA protection against DNase I enzymatic digestion. ${ }^{28}$ Additionally, vectors were visualized by transmission electron microscopy (TEM), and the hydrodynamic diameter and superficial charge of resulting binary and ternary vectors were determined by dynamic light scattering (DLS) and laser Doppler velocimetry (LDV) respectively as elsewhere described. ${ }^{29}$

\subsection{In Vitro Transfection Assays.}

For transfection experiments, ARPE-19 cells were seeded in 24-well plates at an initial density of $7.5 \times 10^{4}$ cells/well with $1 \mathrm{~mL}$ of D-MEM/ F-12 containing $10 \%$ fetal bovine serum (not antibiotic/ antimicotic). When confluence level reached $70-80 \%$, the media was removed, and the cells were exposed to different formulations based on niosome/DNA and protamine/DNA/ niosomes vectors containing $1.25 \mu \mathrm{g}$ of DNA per well. Vectors were diluted in serum-free Opti-MEM I solution and incubated with cells for $4 \mathrm{~h}$ at $37{ }^{\circ} \mathrm{C}$. Following the incubation time, the medium was refreshed with $1 \mathrm{~mL}$ of complete growth medium, and cells were allowed to grow until fluorescence microscopy and flow cytometry analysis.

Qualitative and quantitative expression of EGFP was examined by microscopy (Eclipse TE200-S, Nikon Instruments Europe B.V., Amstelveen, The Netherlands) and flow cytometry (Becton Dickinson Biosciences, San Jose, USA), respectively. Briefly, cells were washed twice with PBS and detached with $300 \mu \mathrm{L}$ of $0.05 \%$ trypsin/EDTA. Then, cells were centrifuged, and the supernatant was discarded. The pellet was resuspended in PBS, diluted in FACS Flow liquid, and directly introduced in the flow cytometer. Transfection efficiency was expressed as the percentage of EGFP positive live cells at $525 \mathrm{~nm}$ (FL1). For cell viability measurements, the BDVia Probe reagent $(5 \mu \mathrm{L})$ was added to each sample to exclude dead cells from the analysis. The fluorescence corresponding to dead cells was measured at $650 \mathrm{~nm}$ (FL3). Control samples (nontransfected cells) were displayed on a forward scatter (FSC) versus side scatter (SSC) dot plot to establish a collection gate and exclude cells debris. Other samples containing Lipofectamine transfected cells without BDVia Probe and nontransfected cells with BD-Via Probe were used as controls to compensate the FL2 signal in FL1 and FL3 channels. For each sample, 10000 events were collected.

\subsection{Intracellular Distribution of DNA.}

DNA distribution inside the cells was evaluated $2 \mathrm{~h}$ after the addition of vectors carrying EMA-labeled DNA by fluorescence microscopy. Prior to the observation of the samples under an inverted fluorescence microscope (Eclipse TE 2000-S; Nikon Corporation, Tokyo, Japan), nuclei were labeled with Hoechst 33342.

\subsection{In Vivo Studies in Rats.}

Six adult male Sprague- Dawley rats (6-7 weeks old, 150-200 g weight) were injected intravitreally and other six rats subretinally. All experimental procedures were carried out in accordance with the Spanish and European Union regulations for the use of animals in research and the Association for Research in Vision and Ophthalmology (ARVO) statement for the use of animals in ophthalmic and vision research and supervised by the Miguel Hernandez 
University Standing Committee for Animal Use in Laboratory. The surgical procedures used for the administration of the vectors in the retina have been previously described elsewhere. ${ }^{29}$

\subsection{Optical Coherence Tomography (OCT).}

Noninvasive in vivo assessment of eye structures was performed using OCT (Spectralis HRA OCT system, Heidelberg Engineering). OCT was performed under general anesthesia induced with an intraperitoneal injection of ketamine $(70 \mathrm{mg} / \mathrm{kg}$, Imalgene; Merial) and diazepam (5 mg/kg, Valium, Roche). Tropicamide 1\% (Colircusi' Tropicamida, Alcon Cusi) was dropped on the eyes to dilate the pupil and give access to a wide panoramic of the fundus. A custom-made contact lens (+25 Diopter) was used to reduce the risk of corneal dehydration and edema and to act as a collimator. Twentyfive $b$-scans with near-infrared (IR) imaging were obtained at standardized position around the optic nerve. All the animals were examined the previous day to the intravitreal or subretinal injections with the intact eyes. This protocol was repeated 14 days and one month postinjection.

\subsection{Analysis of EGFP Expression by Native GFP Fluorescence and Indirect} Immunofluorescence.

To analyze native GFP, whole-mount preparations were performed in both eyes from two rats of each group and were enucleated and immersed for $1 \mathrm{~h}$ in a solution of $4 \%$ paraformaldehyde in PBS. Later, the retinas were dissected as whole-mounts by making four radial cuts. Retinal orientation was maintained by making the deepest radial cut in the superior retina. The retinas were postfixed for $1 \mathrm{~h}$ in the same fixative and rinsed in PBS. Cell nuclei were counterstained with Hoechst 33342 (Sigma) before mounting with antifading media (Invitrogen) for confocal laser scanning microscopy.

For immunohistochemical studies on sagittal sections, both eyes from four rats of each group were enucleated, and the anterior segments, including the lens, were removed. Posterior eyecups were fixed for $1 \mathrm{~h}$ with $4 \%$ paraformaldehyde in $0.1 \mathrm{M}$ PBS followed by several washes in PBS. Samples were then immersed in $30 \%$ sucrose in PBS overnight at $4{ }^{\circ} \mathrm{C}$ for cryoprotection. Eyecups were embedded and oriented in optimal cutting temperature (O.C.T.) compound (Tissue- Tek; Sakura Finetek Europe B.V., Alphen and den Rijn, The Netherlands) and frozen in 2-methylbutane cooled in liquid nitrogen at $-60{ }^{\circ} \mathrm{C}$. Radial sections $(16 \mu \mathrm{m})$ were cut on a cryostat and mounted on SuperFrost Plus microscope slides (VWR International bvba, Leuven, Belgium). Tissue sections were washed with PBS and blocked with blocking solution ( $0.05 \%$ Triton $\mathrm{X}-100,10 \%$ donkey serum, 3\% BSA in PBS) for $1 \mathrm{~h}$. Sections were incubated in primary antibodies: mouse anti- GFP (1:100; Life Technologies), rabbit antiPKC (1:100, Santa Cruz Bioterchnologies), rabbit antirecoverin (1:400, Millipore), rabbit antiNeuN (1:300, Millipore), goat antivimentin (1:100, Santa Cruz Bioterchnologies). Incubation was carried out overnight at room temperature in a humidified chamber followed by rinsing in PBS. Sections were then incubated with fluorescent specifics-secondary antibodies Alexa Fluor 488 donkey antimouse IgG, Alexa Fluor 555 donkey antirabbit IgG, and Alexa Fluor 555 donkey antigoat IgG (Life Technologies) at a 1:100 dilution for $1 \mathrm{~h}$ at room temperature in the dark. Sections were counterstained with Hoechst 33342 (Sigma) and mounted with antifading mounting medium. The specimens were examined with a laser scanning confocal microscope (Leica TCS SPE).

\subsection{Statistical Analysis.}

Statistical analysis was completed with the InStat program (GraphPad Software, San Diego, CA, USA). Differences between groups at significance levels of $95 \%$ were calculated by the Student's $t$ test. In all cases, $\mathrm{P}$ values $<0.05$ were regarded as significant. Normal distribution of samples was assessed by the Kolmogorov-Smirnov test and the homogeneity of the variance by the Levene test. Data were presented as mean \pm SD unless stated otherwise. 

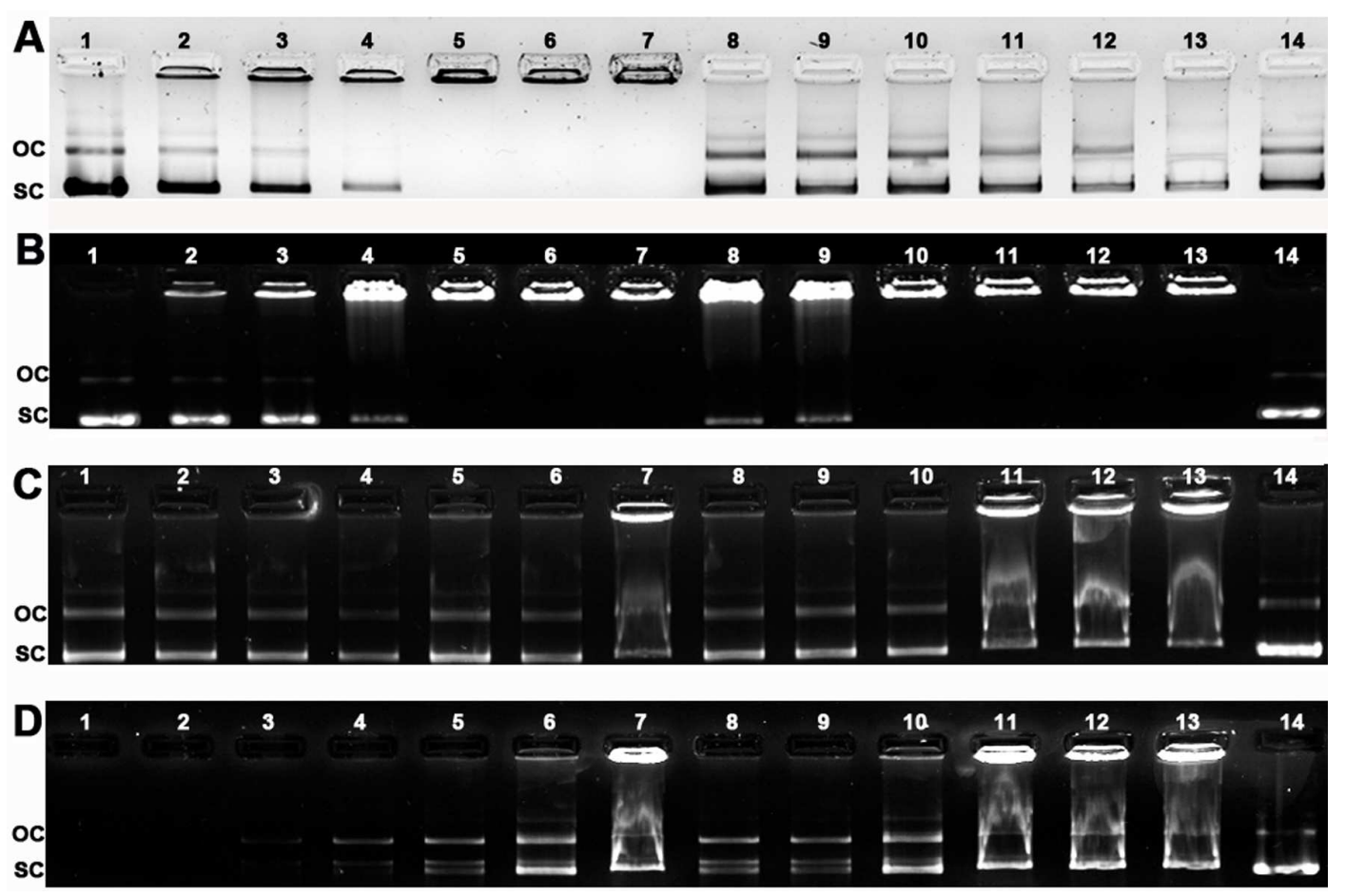

Figure 1. Agarose gel electrophoresis studies. (A) Binding efficiency (lanes 2-7) and release (lanes 8-13) of DNA at different protamine/DNA ratios (w/w). Lane $2=0.25: 1$; lane $3=0.5: 1$; lane $4=1: 1$; lane $5=2: 1$; lane $6=3: 1$; lane $7=4: 1$. Vectors were treated with SDS to release the DNA at different protamine/DNA ratios $(\mathrm{w} / \mathrm{w})$. Lane $8=0.25: 1$; lane $9=0.5: 1 ;$ lane $10=$ 1:1; lane 11 = 2:1; lane 12 = 3:1; lane 13 = 4:1. Lane 1 = free DNA; lane 14 = free DNA + SDS. (B) Binding efficiency of DNA with niosomes (lanes 2-7) and with protamine/DNA/niosomes vectors (lanes $8-13)$ at different ratios of niosome/DNA $(\mathrm{w} / \mathrm{w})$ and protamine/DNA/niosome $(\mathrm{w} / \mathrm{w} / \mathrm{w})$. Lane $2=1: 1$; lane $3=2: 1$; lane $4=5: 1$; lane $5=10: 1$; lane $6=15: 1 ;$ lane $7=30: 1$; lane $8=1: 1: 1 ;$ lane $9=1: 1: 2 ;$ lane $10=1: 1: 5 ;$ lane $11=1: 1: 10 ;$ lane $12=1: 1: 15 ;$ lane $13=1: 1: 30$. Lane 1 and lane 14 = free DNA. (C) Release of DNA from niosomes (lanes 2-7) and from protamine/DNA/niosomes vectors (lanes 8-13) after the addition of SDS at different ratios of niosome/DNA (w/w) and protamine/DNA/niosome (w/w/w). Lane $2=1: 1$; lane $3=2: 1$; lane 4 $=5: 1 ;$ lane $5=10: 1 ;$ lane $6=15: 1 ;$ lane $7=30: 1 ;$ lane $8=1: 1: 1 ;$ lane $9=1: 1: 2 ;$ lane $10=1: 1: 5$; lane 11 = 1:1:10; lane $12=1: 1: 15$; lane $13=1: 1: 30 ;$ lane $1=$ free DNA, lane $14=$ free DNA + SDS. (D) Protection of DNA by niosomes (lanes $2-7$ ) and by protamine/DNA/niosomes (lanes 8-13) from DNase enzymatic digestion at different ratios of niosome/DNA (w/w) and protamine/DNA/niosome $(\mathrm{w} / \mathrm{w} / \mathrm{w})$. After DNase incubation, SDS was added to release the DNA. Lane $2=1: 1 ;$ lane $3=2: 1 ;$ lane $4=5: 1 ;$ lane $5=10: 1 ;$ lane $6=15: 1 ;$ lane $7=30: 1 ;$ lane $8=$ 1:1:1; lane $9=1: 1: 2 ;$ lane $10=1: 1: 5 ;$ lane $11=1: 1: 10 ;$ lane $12=1: 1: 15 ;$ lane $13=1: 1: 30 ;$ lane 1 = free DNA + DNase; lane 14 = free DNA. OC, open circular form; SC, supercoiled form.

\section{RESULTS}

3.1. Condensation, SDS-Induced Release of DNA, and DNase I Protection Assays.

The gel in Figure 1, panel A shows that the capacity of protamine to condense DNA depends strongly on the protamine/DNA ratio. In wells 2 and 3 (protamine/DNA ratios of 0.25:1 and $0.5: 1$ ), the strong intensity of the SC bands (comparable to free DNA on wells 1 and 14) indicates that most of the DNA was free. In well 4 (protamine/DNA ratio of 1:1), faint SC band 
indicates that part of the DNA was not strongly complexed with the protamine. However, from wells 5 to 7 (protamine/DNA ratios of 2:1, 3:1, and 4:1, respectively), no DNA migration was observed, which indicates that at these ratios the DNA was strongly bound to the protamine. After treatment of the complexes with SDS (wells 8-14), the release of DNA was decreased as the protamine/DNA ratio increased. The capacity of the niosome vectors to bind DNA is illustrated in Figure 1, panel B. DNA bands on wells 2-4 (niosome/DNA ratios of 1:1, 2:1, and $5: 1$ ) indicate that part of the DNA was free. From wells 5 to 7 (niosome/DNA ratios of 10:1, $15: 1$, and 30:1), the DNA was totally bound to the niosomes since no SC DNA bands were observed. Regarding the capacity of protamine/ DNA/niosome vectors to bind the DNA (wells 8-13), the faint bands of DNA observed in wells 8 and 9 indicate that at protamine/DNA/niosome ratios of 1:1:1 and 1:1:2, part of the DNA was not tightly complexed with the vectors. However, as the mass ratio of the complexes increased, (wells 10-13 that correspond to protamine/DNA/niosome ratios of $1: 1: 5$ and 1:1:10 and 1:1:15 and 1:1:30, respectively), stronger complexes were formed and detained in the wells, hampering the migration of the DNA through the gel. Wells 1 and 14 correspond to free DNA. The release of the DNA upon the addition of SDS was examined in Figure 1, panel C. DNA release from niosomes (well 2-7) was successfully achieved at all ratios (from 1:1 to 30:1), although in well 7 (niosome/DNA ratio of 30:1), part of the DNA did not migrate and was retained in the well. Regarding the capacity of SDS to release DNA from protamine/DNA/niosome vectors (wells 8-13), free DNA bands were observed at low mass ratios (wells 8-10, which correspond to ratios of 1:1:1, 1:1:2, and 1:1:5). However, when the mass ratio of the complexes increased (wells 11-13, which correspond to ratios of 1:1:10, 1:1:15, and 1:1:30, respectively), stronger complexes were formed hampering the migration of the plasmid, even upon the addition of SDS. Well 1 corresponds to free DNA and well 14 to free DNA treated with SDS. DNA protection from enzymatic digestion was analyzed in Figure 1, panel $D$. The absence of bands on wells 2 and 3 (niosome/DNA ratios of 1:1 and 2:1) indicates that the plasmid was completely degraded by the enzyme, as succeeded in well 1 (free DNA treated with DNase I). As the niosome/ DNA ratio increased $(5: 1,10: 1$, and $15: 1$, which correspond to wells 4,5 , and 6$)$, more intense SC bands were observed. At 30:1 ratio (well 7), part of the protected DNA was detained in the well. Regarding protamine/DNA/niosome vectors (wells 8-13), the SC bands were more intensive as the mass ratio of the complexes increased (wells $8-10$, which correspond to ratios of 1:1:1, 1:1:2, and 1:1:5). However, at higher mass ratios (wells 11-13, ratios of 1:1:10, 1:1:15, and 1:1:30, respectively), part of the protected DNA was retained in the well and did not migrate through the agarose matrix. Well 14 correspond to free DNA.

\subsection{Particle Size, Zeta Potential, and TEM of the Vectors.}

Vectors were physicochemically characterized in terms of size, zeta potential, and morphology (Figure 2). As shown in Figure 2, panel $A_{1}$, the particle size of protamine/ DNA complexes decreased as the protamine/DNA ratio increased (210 nm at 0.25:1 mass ratio, and $125 \mathrm{~nm}$ at 4:1 mass ratio). By contrast, zeta potential value increased proportionally to the mass ratio (-30 mV at 0.25:1 mass ratio, and $16 \mathrm{mV}$ at 4:1 mass ratio). Protamine/DNA complexes at 1:1 mass ratio exhibited a heterogeneous morphology when assessed by TEM, as illustrated in Figure 2, panel $A_{2}$. Regarding niosome/DNA binary vectors, particle size also decreased with the mass ratio from $180 \mathrm{~nm}$ at $1: 1$ mass ratio to $135 \mathrm{~nm}$ at 30:1 mass ratio (Figure $2 \mathrm{~B}_{1}$ ). Negative zeta potential values were observed at low niosome/DNA ratios ( $-31 \mathrm{mV}$ and $-23 \mathrm{mV}$ at 1:1 and 2:1 mass ratios, respectively). First positive zeta potential value (30 mV) was observed at 5:1 mass ratio, and from this point, zeta potential slightly increased until a maximum of $39 \mathrm{mV}$ at 30:1 mass ratio. At 15:1 niosome/DNA mass ratio, vectors exhibited a discrete spherical morphology (Figure $2 B_{2}$ ). Ternary protamine/DNA/noisome vectors formulated at a fixed protamine/DNA ratio of 1:1, and increasing proportions of niosomes slightly changed particle size, which ranged from $160 \mathrm{~nm}$ at 1:1:1 protamine/DNA/ niosome ratio to $130 \mathrm{~nm}$ at 1:1:30 protamine/DNA/noisome ratio (Figure2 $\mathrm{C}_{1}$ ). At 1:1:1 mass ratio, zeta 
potential value was slightly negative $(-2.0 \mathrm{mV})$. The rest of the ratios resulted in positive zeta potential values, which ranged from $27 \mathrm{mV}$ at 1:1:2 mass ratio to $43 \mathrm{mV}$ at 1:1:30 mass ratio. Discrete spherical shapes were observed when protamine/DNA/ niosome ternary vectors were examined under TEM (Figure $2 \mathrm{C}_{2}$ ).

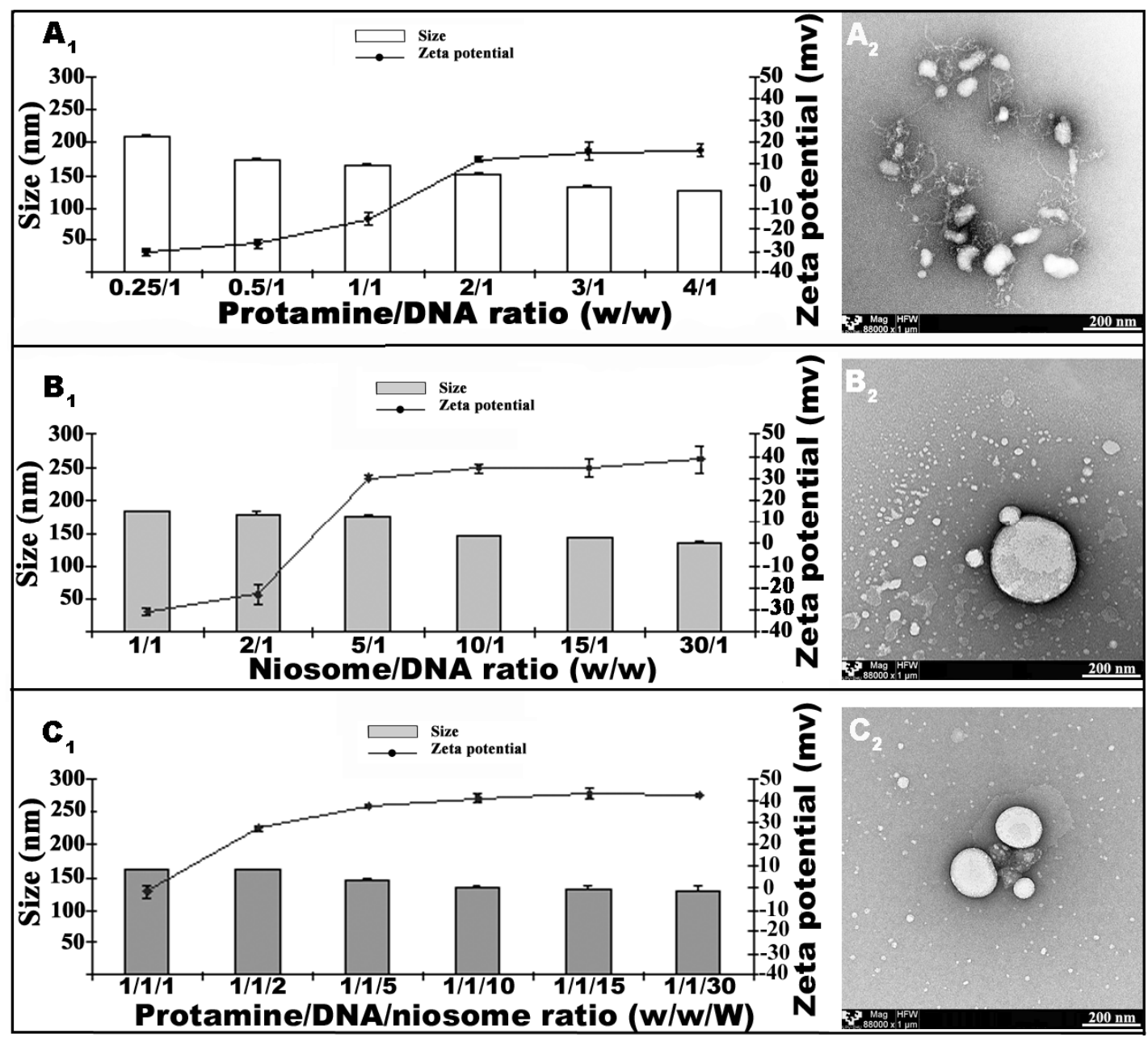

Figure 2. Vectors characterization in terms of particle size, zeta potential, and morphology at different mass ratios. $\left(A_{1}\right)$ Effect of protamine/DNA ratio on particle size (bars) and zeta potential (lines). (mean $\pm S D, n=3$ ). $\left(A_{2}\right)$ TEM image of protamine/DNA vectors at 1:1 mass ratio. Original magnification $88.000 \times$. Scale bar $=200 \mathrm{~nm}$. $\left(B_{1}\right)$ Effect of niosome/DNA ratio on particle size (bars) and zeta potential (lines). (mean $\pm S D, n=3$ ). ( $\left.B_{2}\right)$ TEM image of niosome/DNA vectors at 15:1 mass ratio. Original magnification $88.000 \times$. Scale bar $=200 \mathrm{~nm}$. $\left(\mathrm{C}_{1}\right)$ Effect of protamine/DNA/ niosome ratio on particle size (bars) and zeta potential (lines). (mean $\pm S D, n=3)$. $\left(C_{2}\right)$ TEM image of protamine/DNA/niosome vectors (1:1:5 mass ratio). Original magnification $88.000 \times$. Scale bar $=200 \mathrm{~nm}$. 

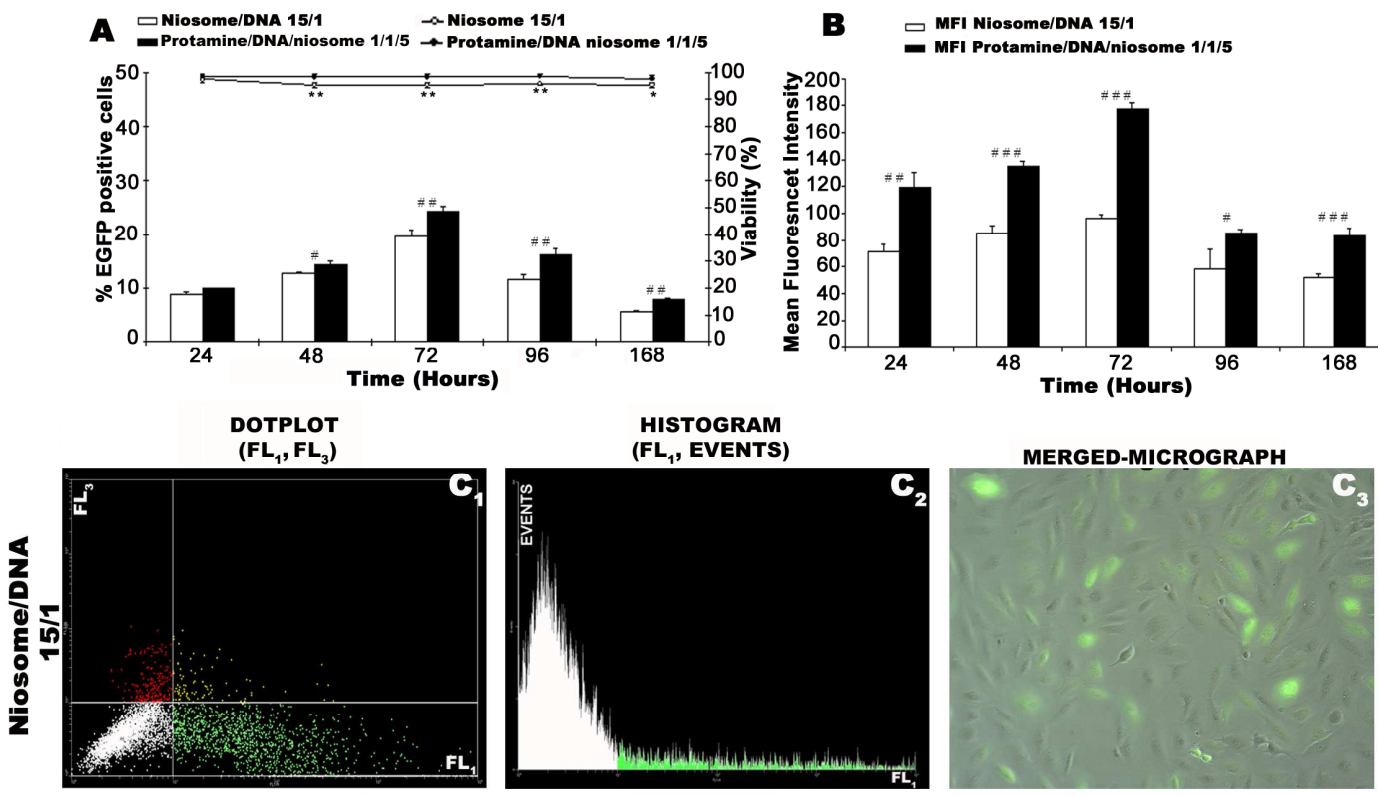

HISTOGRAM
(FL ${ }_{1}$, EVENTS)

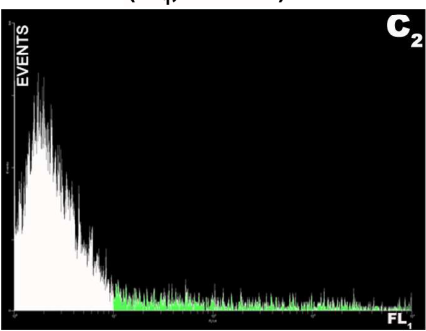

MERGED-MICROGRAPH
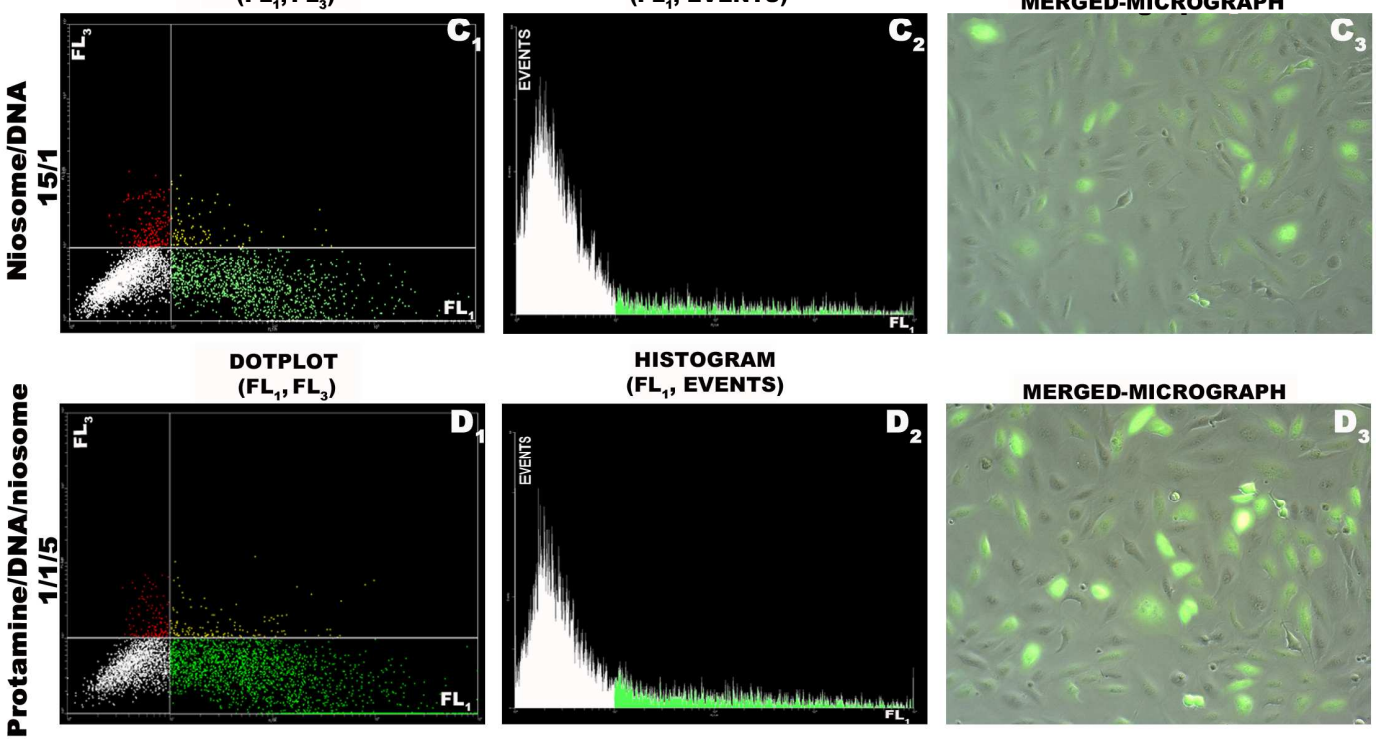

Figure 3. Transfection efficiency of niosome/DNA (15:1, w/w ratio) and protamine/DNA/niosome $(1: 1: 5, \mathrm{w} / \mathrm{w} / \mathrm{w}$ ratio) vectors at different times after the addition of the vectors in ARPE-19 cells. (A) Bars represent the percentage of transfected cells after the addition of niosome/DNA vectors (white bars) and protamine/DNA/niosome vectors (black bars). Lines represent the percentage of viable cells after the addition of niosome/DNA DNA (white circles) and protamine/DNA/niosome vectors (black circles). Mean $\pm S D ; n=3$. ( $^{*} P<0.01$; $\left.{ }^{*} * \mathrm{P}<0.001\right)$. (B) Mean fluorescent intensity (MFI) of cells transfected with niosome/DNA (white bars) and protamine/DNA/niosome vectors (black bars). Mean $\pm S D ; n=3$. (\#P<0.01; \#\#P $<0.001$; \#\#\#P<0.0001). (C1-C3) Flow cytometry dot-plots (FL1-FL3), histograms (FL1), and overlay phase-contrast micrograph with fluorescent illumination (GFP channel) of cells transfected with niosome/DNA vectors. (D1-D3) Flow cytometry dot-plots (FL1-FL3), histograms (FL1), and overlay phase-contrast micrographs with fluorescent illumination (GFP channel) of cells transfected with protamine/DNA/niosome vectors. FL1 channel corresponds to EGFP and FL3 channel to 7-AAD. Original magnification 20x.

\subsection{Transfection and Cell Viability Studies.}

Transfection efficiency and cell viability over time were studied in ARPE-19 cells (Figure 3). As observed in Figure 3, panel A, the percentages of transfected cells (bars) were higher with the ternary vectors containing protamine at all the evaluated times. Statistical differences between both groups were obtained at $48,72,96$, and $168 \mathrm{~h}$ post-transfection. The maximum percentage of transfected cells was obtained at $72 \mathrm{~h}$ post-transfection for both niosome/DNA $(19 \%)$ and protamine/DNA/noisome $(26 \%)$ vectors. Both values were clearly inferior to those 
previously reported when commercial Lipofectamine 2000 was used to transfect ARPE-19 cells, around 50\%.29 Regarding cell viability (Figure 3A, lines), niosome/DNA binary vectors were significantly more toxic to ARPE-19 cells $48 \mathrm{~h}$ post-transfection until the end of the experiment. In any case, cell viability was over $94 \%$ in all the studied conditions, a value clearly superior to that obtained when ARPE-19 cells were transfected with Lipofectamine 2000 (around 75\%, data not shown). To further relate the percentage of transfected cells and the level of protein expression, we measured the mean fluorescent intensity (MFI) of transfected cells (Figure 3B). For both formulations, MFI increased gradually from 48 to $72 \mathrm{~h}$ post-transfection, and at this point, MFI reached the maximum value and decreased gradually until the end of the experiment. At all tested times, MFI of protamine/DNA/niosome ternary vectors was significantly higher when compared with niosome/DNA binary vectors. Under microscopic examination, ARPE-19 cells exhibited a healthy morphology at $72 \mathrm{~h}$ post-transfection with both niosome/DNA and protamine/DNA/niosome vectors (Figure 3C3 and D3, respectively). Figure 3 , panels $\mathrm{C} 1$ and $\mathrm{C} 2$ represent flow cytometry dot-plots (FL1-FL3) and histograms (FL1) of ARPE-19 cells at $72 \mathrm{~h}$ post-transfection with niosome/ DNA vectors. Similarly, Figure 3, panels D1 and D2 represent flow cytometry dot-plots (FL1-FL3) and histograms (FL1) of cells at $72 \mathrm{~h}$ post-transfection with ternary protamine/DNA/ niosome ternary vectors.

\subsection{Detection of Intracellular EMA Labeled DNA by Fluorescence Microscopy.}

Figure 4 represents fluorescent images of ARPE-19 cells $2 \mathrm{~h}$ after the addition of naked DNA (Figure $4 A_{1}-A_{4}$ ), binary niosome/DNA vectors at 15:1 mass ratio (Figure $4 B_{1}-B_{4}$ ), and ternary protamine/DNA/noisome vectors at 1:1:5 mass ratio (Figure $4 C_{1}-C_{4}$ ) containing EMA labeled DNA. The absence of red fluorescence in Figure 4, panel $A_{3}$ suggests that the plasmid was not internalized by the cells when added alone. At high magnification, we observed a homogeneous distribution of the red fluorescence in the cytoplasm and nucleus of cells treated with niosome/DNA vectors (Figure $4 D_{1}$ ); however, when cells were treated with protamine/DNA/niosome vectors, the DNA was more condensed, red fluorescence was more intense, and the DNA was mainly observed inside the nucleus rather than in the cytoplasm (Figure $4 D_{2}$ ). 


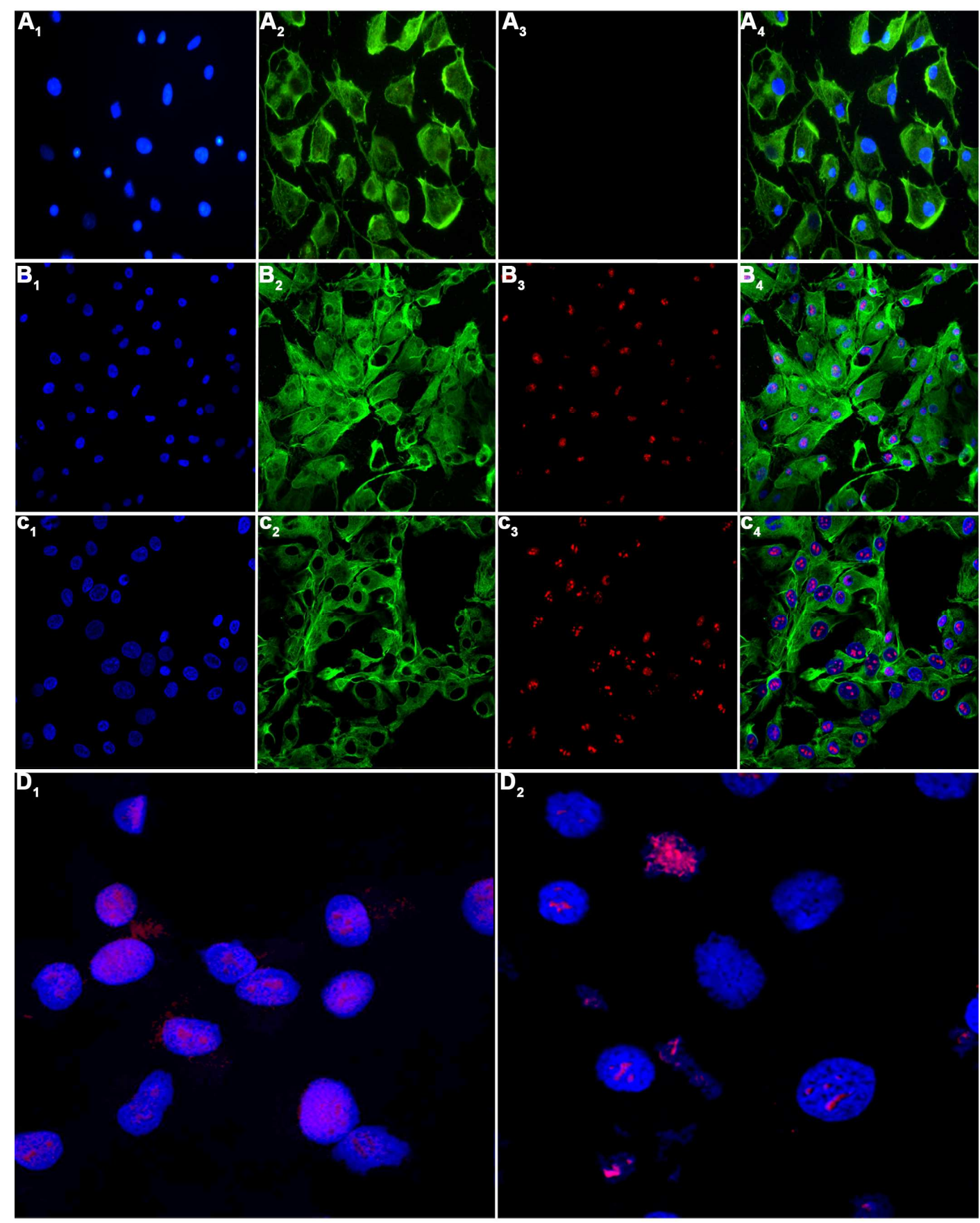

Figure 4. Fluorescent microscopy images of ARPE-19 cells $2 \mathrm{~h}$ after the addition of $\left(A_{1}-A_{4}\right)$ naked-DNA, $\left(B_{1}-B_{4}\right)$ niosome/DNA vectors at 15:1 ratio, and $\left(C_{1}-C_{4}\right)$ protamine/DNA/niosome vectors at 1:1:5 ratio. Blue color shows cell nuclei stained with Hoeschst 33258 , and green color shows F-actin stained with Phalloidin. Red color shows EMA-labeled pCMS-EGFP plasmid. $\left(\mathrm{A}_{4}-\mathrm{C}_{4}\right)$ Merged images of ARPE-19 cells after the addition of naked-DNA, niosome/DNA vectors at 15:1 ratio, and protamine/DNA/niosome vectors at 1:1:5 ratio, respectively. Original magnification 10x. ( $D_{1}$ and $\left.D_{2}\right)$ Images at $60 \times$ magnification of ARPE-19 cells after the addition of niosome/DNA and protamine/DNA/noisome vectors, respectively. 


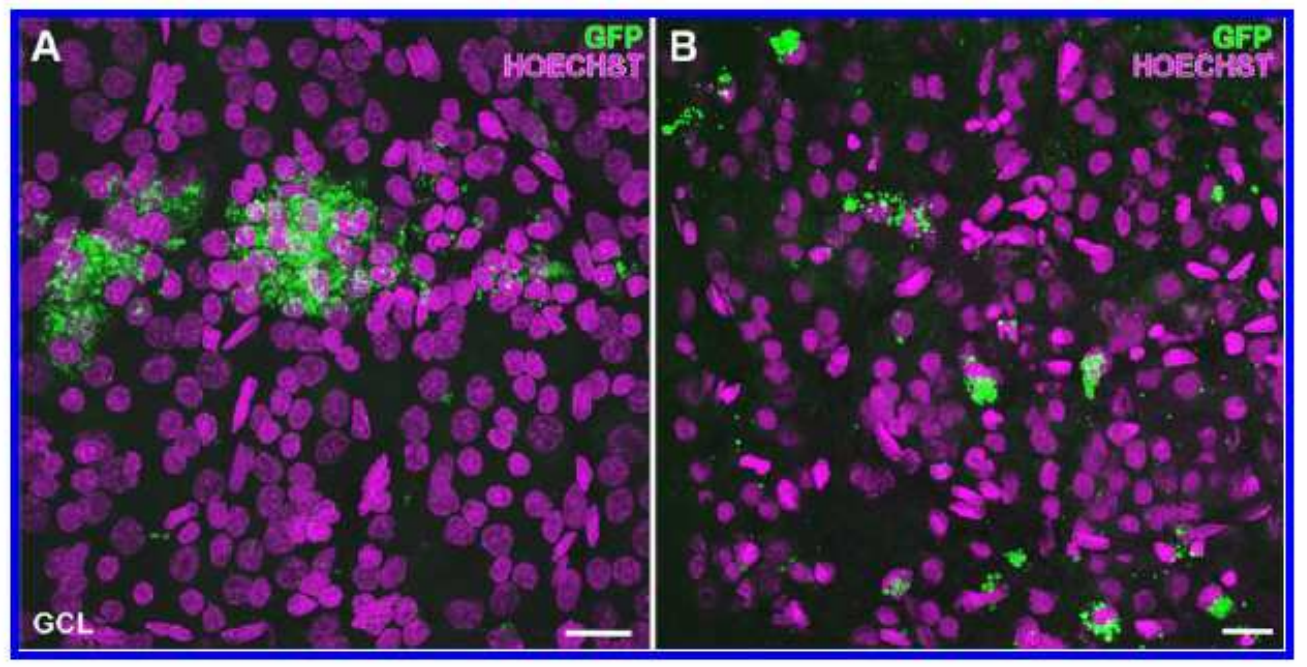

Figure 5. In vivo gene expression of EGFP after administration of protamine/DNA/niosome ternary vectors at 1:1:5 mass ratio to rats 1 month post $(A)$ subretinal and $(B)$ intravitreal injections. When ternary vectors were subretinally and intravitreous injected, native EGFP expression (in green) was observed in wholemount preparations. (A) Intense GFP+ cell bodies accumulations are found in the ganglion cell layer. (B) Many retinal cells show GFP fluorescence, and scattered cells show a cytoplasm ganglion cell-like morphology. Cell nuclei were counterstaining with Hoechst 33342 (pseudocolored in magenta). GCL, ganglion cell layer. Scale bar $=20 \mu \mathrm{m}$.

\subsection{In Vivo EGFP Expression.}

At 1 month after injection, the optical coherence tomography study of injected eyes demonstrated no changes in the retina (Figure 2, Supporting Information) other than a small bleed around the injection site (data not shown). Subretinal and intravitreal injections did not harm the retinal integrity. There was no evidence of retinal toxicity secondary to administrations.

EGFP expression in rat retinas was detected 14 days and 1 month after subretinal and intravitreal administrations of protamine/DNA/niosome ternary vectors at 1:1:5 mass ratio (Figures 5-7). The analysis of the native EGFP expression on wholemount retinas after 1 month of the administrations revealed EGFP-expressing cells in the ganglion cell layer (Figure 5), and no fluorescence was detected in control retinas (data not shown). Retinal wholemounts subretinally injected showed accumulations with strong GFP expression close to the site of injection in the ganglion cell layer (Figure 5A). In contrast, disperse GFP positive retinal ganglion cells were detected in the retina with intravitreal administration (Figure 5B).

Immunohistochemical staining of GFP and several retinal markers in rat retinas after 14 days postinjection showed levels of protein expression strongly varied depending on the location of the injection (Figure 6). Transfection of RPE cells and photoreceptor layer was most efficiently achieved by subretinal administration of ternary vectors (Figure $6 \mathrm{~A}-\mathrm{C}$ ). In addition, we found some postsynaptic terminal of rod bipolar cells (marked with PKC) contacting with processes GFP positive in the inner plexiform layer. Subretinal injection induces a bleb of concentrated vector in intimate contact with photoreceptors and RPE; thus, GFP expression was mainly observed in the cells close to the place of the injection in the retinal pigment epithelium (RPE) (Figure 6A), the photoreceptor outer segments (Figure 6B), and outer nuclear layer labeled with recoverin (Figure 6C). After intravitreal injections, we observed GFP expression distributed mainly in the ganglion cell layer $(G C L)$ and Müller cells prolongations in the inner retina (Figure 6D,E) as well as some processes at the inner nuclear layer (Figure 6D). 
Subsequently, the immunolabeling was perfomed in the contralateral eyes (control eyes), and no GFP expression was detected (data not shown).

The study of the retinas 1 month after subretinal administration revealed GFP expression predominantly in ganglion cells (NeuN-positives) and their prolongations (Figure 7A,B). Additionally, 1 month after intravitreal injection, GFP partially colocalized with Müller glial cell labeled with vimentin (Figure 7C). There was no evidence of GFP expression in eyes that were used as control.

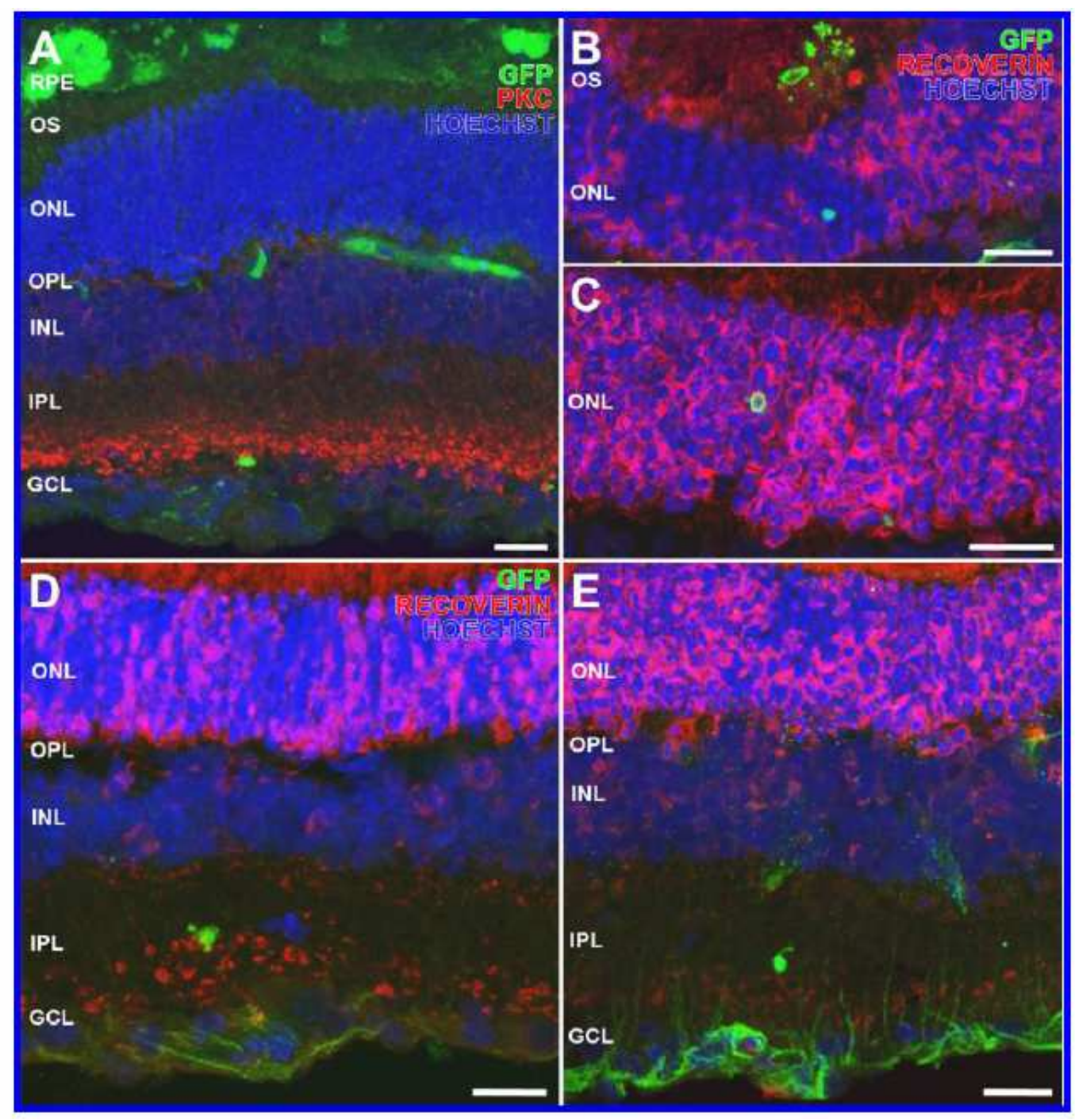

Figure 6. Immunohistochemical study of EGFP expression in retinal cross-sections 14 days after subretinal and intravitreal administration of protamine/DNA/niosome ternary vectors at 1:1:5 mass ratio. Doble immunolabeling of $(A-C)$ subretinal and $(D, E)$ intravitreal injection with GFP (green), (A) PKC in red, or (B-E) recoverin in red. (A) Confocal image of retinal cross-section shows that GFP expression was localized in the retinal pigment epithelium layer, ganglion cell layer, and some blood vessel. (B) GFP was localized to some outer segments of photoreceptors, and (C) only an occasional photoreceptor double-labeled for GFP and recoverin can be found. Panels D and E show GFP signal in ganglion cell layer, and (D) some processes in the inner plexiform layer are GFP positive. Cell nuclei were counterstaining with Hoechst 33342 (pseudocolored in blue). RPE, retinal pigment epithelium layer; OS, outer 
segments; ONL, outer nuclear layer; OPL, outer plexiform layer; INL, inner nuclear layer; IPL, inner plexiform layer; GCL, ganglion cell layer. Scale bar $=20 \mu \mathrm{m}$.

\section{DISCUSSION}

Nonviral retinal gene therapy offers reasonable hope to address many devastating binding disorders that affect the retina, ${ }^{7}$ although new safe and effective vectors need to be developed to be considered as a mainstream medicine option. In a previous work, we have already demonstrated the capacity of novel niosomes based on the 2,3di(tetradecyloxy)propan-1-amine cationic lipid combined with squalene and polysorbate 80 to transfect efficiently the rat retina with the reporter pCMS- EGFP plasmid.18 In this work, we evaluated the incorporation of protamine to our niosome formulation to progress in the design and develop new nonviral vectors for retinal gene delivery purposes.

Generally, nonviral vector complexes are formed as a result of the electrostatic interactions between the cationic charges of the vectors and the anionic charges of the DNA. ${ }^{24}$ To further study these electrostatic interactions, we performed an agarose gel electrophoresis assay (Figure 1) since an optimum equilibrium between gene condensation and release is required to increase transfection efficiency. ${ }^{20}$ As expected, the capacity of protamine to condense the DNA depended on the protamine/ DNA ratio (Figure 1A). A protamine/DNA ratio of at least 2:1 was required to condense all DNA. At this ratio, the electrostatic interactions between protamine and DNA were strong enough to hamper the diffusion of free DNA through the agarose matrix (Figure 1A, well 5); however, at a lower ratio (protamine/DNA 1:1, well 4), the amount of protamine was not enough to totally condense the DNA. DNA migration induced by SDS treatment was hampered as the protamine/ DNA ratio increased. Therefore, we selected the 1:1 protamine/ DNA mass ratio as the optimal ratio to further elaborate ternary protamine/DNA/niosome vectors. We therefore hypothesize that the unbound DNA at this proportion could be further retained in the formulation upon the addition of cationic niosomes. Likewise, at this mass ratio, DNA was easily released from protamine (Figure 1A, well 10), which is an important factor for gene delivery applications. ${ }^{24}$ Gel electrophoresis assay (Figure 1B) also showed that the presence of protamine at 1:1 mass ratio increased the DNA condensation capacity of the protamine/DNA/niosome vectors (Figure 1B, well 5); however, when protamine was incorporated into the ternary vectors, only a niosome/DNA ratio of 5:1 was enough to condense all the DNA in the protamine/DNA/noisome formulation (Figure 1B, well 10, 1:1:5 mass ratio). Figure 1, panel $C$ shows that all niosome/DNA ratios, except 30:1, were able to release DNA in the presence of SDS; however, ternary vectors retained DNA in the wells at niosome/DNA ratios over 10:1 (Figure 1B, well 11, 1:1:10), which corroborates the assumption that protamine at 1:1 mass ratio increased the DNA condensation capacity. DNA can be easily degraded by nucleases in the cytosol. ${ }^{30}$ Therefore, it is essential to study the DNA protection capacity of nonviral carriers to design efficient vectors for gene delivery purposes. Figure 1, panel $D$ shows that niosome vectors at 15:1 mass ratio were able to protect and release DNA from enzymatic digestion since a clear SC band was observed on the gel (Figure1D, well 6). The lower protection capacity (SC bands), observed at mass ratios below 15:1, was probably due to a lower condensation degree of the DNA in the complexes, which was more exposed to the digestion mediated by the enzymes. At higher mass ratios (30:1, Figure 1D, well 7), part of the protected DNA was detained in the well, which indicates that the electrostatic interactions were strong enough to hamper the release of the DNA. Regarding the ternary vectors, clear SC bands were observed at 1:1:5 protamine/DNA/niosome mass ratios (Figure 1D, well 10). At higher niosome ratios, the strong electrostatic interactions hampered the diffusion of the protected DNA. These results emphasize the importance of the delicate balance between DNA condensation capacity to protect DNA from DNases, and DNA release, since an excess DNA condensation hampers plasmid release and transfection; by contrast, a low condensation will not protect DNA. ${ }^{31}$ 
To correlate the agarose gel electrophoresis results with changes in particle size and superficial charge of the vectors, we performed DLS and LDV measurements to determine the hydrodynamic diameter and the superficial charge of the vectors. Additionally, the morphology of the vectors was analyzed by TEM (Figure 2). Adding DNA to the niosomes at a 15:1 niosome/DNA mass ratio formed lipoplexes, which adopted a discrete spherical morphology (Figure $2 \mathrm{~B}_{2}$ ), the most favorable structure from an energetic point of view. ${ }^{32}$ The incorporation of protamine in the ternary vectors at a 1:1:5 protamine/DNA/niosome mass ratio did not change significantly the morphology (Figure $2 \mathrm{C}_{2}$ ). In Figure 2, panel $\mathrm{A}_{1}$, we observed, as aforementioned in the agarose gel electrophoresis assay, that the capacity of protamine to condense the DNA depended on the protamine/DNA mass ratio since particle size of complexes clearly decreased as the mass ratio increased (Figure $2 \mathrm{~A}_{1}$ ) due to the stronger electrostatic interactions that condense DNA more efficiently. Likewise, the highest zeta potential values observed at high mass ratios could explain the stronger electrostatic interactions that results in a more efficient DNA condensation, and therefore the size of protamine/DNA complexes was reduced. ${ }^{20}$ Interestingly, zeta potential values of protamine/DNA complexes at 1:1 mass ratio exhibited a negative zeta potential value of -15 $\mathrm{mV}$, which could explain the faint SC bands observed in Figure 1, panel A, well 4, because at this ratio, the amount of protamine was not enough to condense all the DNA. Additionally, negative zeta potential value of protamine/DNA complexes at 1:1 mass ratio could enhance electrostatic interactions with cationic niosomes when these are added to formulate protamine/DNA/niosome ternary vectors. From Figure 2, panel $\mathrm{B}_{1}$, we observed that niosome/ DNA vectors required a 5:1 mass ratio to achieve the first positive zeta potential values (Figure $2 \mathrm{~B}_{1}$ ) and retain most of the DNA (Figure1B, well 4); however, when protamine was incorporated to formulate protamine/DNA/niosome ternary vectors, only a 2:1 niosome/DNA ratio was required to obtain positive zeta potential values (Figure $2 C_{1}$ ) and condense most of the DNA (Figure1B, well 9). The smaller amount of niosome required to obtain positive zeta potential values in ternary vectors can be attributed to the partial neutralization between the anionic DNA and the positive protamine.

Regarding particle size, we observed that ternary vectors were smaller than the counterpart niosome/DNA binary vectors at all tested ratios, which corroborates the assumption that DNA is more condensed when protamine is added to the formulation. Although it has been described that the size of nanoparticles clearly rules cellular uptake and therefore transfection efficiency, ${ }^{33,34}$ nowadays there is not a clear consensus about the optimum particle size of nonviral vectors for gene delivery purposes. In any case, the sizes of the vectors reported in our work slightly ranged from 120-180 nm at different conditions (Figure $2 \mathrm{~B}_{1}, \mathrm{C}_{1}$ ) and clearly were into the nanorange scale, which has been reported that enhances intracellular uptake when compared with the microrange scale. ${ }^{35}$ The surface charge of nonviral vectors is another parameter that needs to be considered. A final positive charge on the surface of the vectors is a desirable condition since it enhances electrostatic interactions with negatively charged cellular membranes and the posterior uptake into the cell. ${ }^{20}$

On the basis of the physicochemical characteristics of the vectors in terms of DNA condensation, protection, release, particle size, morphology, and superficial charge, we selected niosome/DNA binary and protamine/DNA/niosome ternary vectors at 15:1 and 1:1:5 mass ratios respectively for in vitro transfection studies in ARPE-19 cells. At these ratios, both vectors were able to condense, protect, and release the DNA. Additionally, cationic spherical nanoparticles were obtained with adequate characteristics for gene delivery applications.

ARPE-19 cells represent a good in vitro model to evaluate transfection systems aimed to treat inherited retinal diseases. These cells play a major role in ocular inherited diseases associated with senescence and dystrophies of the photoreceptors and mutations in genes of these cells can lead to photoreceptor death. ${ }^{36}$ In addition, these cells divide slowly, which could explain the difficulties found by some authors to get high transfection efficiencies ${ }^{37}$ since 
the passage of the DNA into the nucleus is hampered in slowly dividing cells as ARPE-19. ${ }^{38}$ Therefore, to transfect efficiently this cell line, we incorporated to our niosome formulation protamine at an appropriate mass ratio based on our previous characterization studies and because of the reported flattering properties of protamine to promote active nuclear transport through the nuclear pore complex due to the rich sequences in arginine. ${ }^{19}$ However, protamine/DNA vectors by themselves were not able to transfect ARPE-19 cells (data not shown), which is in agreement with data reported by other authors. ${ }^{20,21}$ One possible reason may be the high hydrophilicity of the protamine, which could hamper the entry through cellular membrane. ${ }^{21}$ To overcome this scenario, we prepared protamine/ DNA/niosome ternary vectors, and the transfection efficiency and cell viability of this formulation on ARPE-19 cells were compared with niosome/DNA binary vectors (Figure 3). Interestingly, we observed that the percentage of transfection and the cell viability was statistically higher in ternary vectors (Figure3A). However, in rapidly dividing cells such as HEK- 293, in which nuclear entry should not be a limiting factor for transfection efficiency due to the nuclear membrane disruption during the mitosis process, the incorporation of protamine did not increase transfection efficiency. ${ }^{20}$ These results suggest that the addition of protamine to lipid-based formulations could be an interesting approach to increase transfection in slowly dividing cells and probably in postmitotic cells found in the retina. To have some evidence of the level of protein expression, we also measured the MFI of the transfected cells (Figure 3B). Our results showed that the MFI of transfected cells by ternary protamine/DNA/niosome vectors was statistically higher when compared with the binary vectors. Therefore, we can conclude that the incorporation of protamine ${ }^{39}$ to niosome/DNA vectors not only increased the percentage of transfected cells, but also the amount of protein expression, which has significant relevance for clinical applications. Regarding the cytotoxic effect of the formulations, we observed that protamine/DNA/niosome ternary vectors at 1:1:5 mass ratio were clearly better tolerated by ARPE-19 cells than their counterparts niosome/DNA binary vectors at 15:1 mass ratio (Figure3A, lines). Classically, the toxicity of lipoplexes has been associated with the induction of apoptosis and has been clearly correlated with the amount of the cationic lipid in the formulation. ${ }^{40}$ Our protamine/DNA/niosome ternary vectors were formulated at a niosome/DNA ratio of 5:1, three-times lower that the 15:1 mass ratio of the binary vectors, which could explain its lower cytotoxicity. Therefore, protamine/ DNA/niosome ternary vectors at 1:1:5 mass ratio transfected ARPE-19 cells more efficiently than the binary vectors based niosome/DNA at 15:1 mass ratio and were better tolerated by the these cells.

To explain the differences observed in the transfection efficiency between both binary and ternary vectors in ARPE-19 cells, we investigated the intracellular distribution of DNA in both binary vectors (niosome/DNA, 15:1 mass ratio) and ternary vectors (protamine/DNA/niosome, 1:1:5 vectors) $2 \mathrm{~h}$ after the addition of the formulations. For this purpose, DNA was labeled with EMA, a red fluorescent DNA intercalating agent. As observed in Figure 4, the DNA was much more condensed after the treatment of the cells with the formulation containing protamine (Figure 4D2). In addition, most of the DNA was inside the nucleus. By contrast, the binary formulation without protamine presented a more homogeneous distribution of the DNA through the nucleus and cytoplasm. These findings confirm the excellent properties of protamine to improve DNA packaging (which prevents degradation by different cytoplasmic agents such as DNases) and promote DNA delivery into the nucleus by means of nuclear localization sequences. ${ }^{24,41}$ This issue is especially important in slow dividing cells, such as ARPE-19, since the entry of DNA into the nucleus is hampered by the nuclear membrane. However, differences on transfection efficiencies between both binary and ternary vectors could be due to not only the nuclear enhancing properties of protamine into slow dividing cells, but also to the differences on the endocytosis mechanism. For instance, it has been reported that the components of the formulation such as sweet arrow peptide and dextran may have particular features to change the endocytosis mechanism and, consequently, the transfection efficiency when they are added to lipid-based formulations. ${ }^{38,42}$ 
Regarding protamine, it has been reported that it can change the internalization route when added to solid lipid nanoparticles in a clear cell-dependent manner. ${ }^{20}$ Interestingly, in this last study, authors observed a shift in the internalization pathway from caveolae/raft-mediated to clathrin- mediated endocytosis in ARPE-19 cells when protamine was incorporated into DNASLN vectors. Genes internalized by clathrin-mediated endocytosis pathway are usually entrapped in endosomes, which fuse with lysosomes and result in the degradation of the content. 43 Therefore, to get efficient gene expression through this pathway, a timely release of the DNA from the endosome into the cytoplasm is required. We have recently reported that incorporation of squalene (a precursor of the cholesterol synthesis) to our cationic niosome formulation could enhance endosomal scape, resulting in high levels of gene expression when clathrin-mediated endocytosis commands the internalization process. ${ }^{18}$ By contrast, the lack of lysosomal activity in the caveosomes could explain, at least in part, the lower transfection efficiency found in ARPE-19 cells when caveolae mediated endocytosis is involved in the internalization mechanism since the release of the DNA from the niosome can be hampered when particles are internalized by this route. Therefore, we hypothesize that a similar shift in the internalization pathway from caveolae/raft-mediated to clathrin- mediated endocytosis could happen when protamine is added to our niosome/DNA vectors. However, and considering that one of the main roles of ARPE-19 cells is the phagocytosis of shed photoreceptors, the phagocytic capacity and other endocytic routes of ARPE-19 cells (up to nine different endocytosis routes have been differentiated) should be also considered to further analyze the role of protamine on transfection efficiency mediated by niosomes.

We carried out a preliminary in vivo study to evaluate the transfection efficiency and toxicity of protamine/DNA/ niosome ternary vectors at 1:1:5 mass ratio 14 days after intravitreal and subretinal injections. Gene delivery by intravitreal injection has been extensively studied as a relatively easy way to deliver high doses in the retina structures. Classically, after intravitreal injection, high protein expression is typically observed in the ganglion cell layer and in some cells of the inner nuclear layer, ${ }^{39,44}$ which is in agreement with data observed 14 days after intravitreal administration in Figure 6, panels $D$ and $E$, where some ganglion and their processes and Müller cells expressed the green fluorescent protein. Transfection at this level could have relevant clinical implication for the treatment of glaucoma, which is the first cause of visual disability and blindness worldwide. However, one of the biggest challenges of intravitreal injection is to target the outer segments of the photoreceptors and the RPE without causing harm to the sensitive neural tissue ${ }^{7}$ since most of the inherited retinal diseases such as Stargat Disease, Retinitis Pigmentosa, Age-related Macular Degeneration, or Leber Congenital Amaurosis are due to defects of genes at this level. ${ }^{45}$ By contrast, injections of vectors into the subretinal space allow the direct contact of the nucleic acids with photoreceptors, outer retinal layers, and RPE cells. ${ }^{46}$ Therefore, this route of administration could be appropriate to treat the aforementioned retinal inherited diseases. However, there is a high risk of retinal detachment or lesion in the retina after subretinal injection. In any case, promising results have been obtained in clinical trial after subretinal injection to treat many inherited retinal diseases such as Leber Congenital Amaurosis Type $2 .{ }^{47}$ As observed in Figure 6, panels A-C, we found high levels of protein expression in photoreceptors (and outer segments) and in the RPE 14 days after subretinal injection. We further evaluated transfection efficiency 1 month after both intravitreal and subretinal injections since long-term transgene expression is integral to success of any gene therapy intervention to reduce the frequency of invasive intravitreal and subretinal administration to patients affected. After 1 month of both subretinal and intravitreal injections, we observed a decrease in the number of cells transfected (Figures 5 and 7), probably due to the episomal nature of the plasmid and gene silencing procedures. However, when time is a crucial factor, we should consider important differences in anatomy, physiology, development, and biological phenomena between rats and humans. For instance, it has been estimated 30 days of human life for every day of life of the rat. ${ }^{48}$ Taking into 
account these considerations, we can argue that persistence of transfection efficiency 14 days and 1 month after the injections in rats is a reasonable period of time to think on clinical translation. In any case, different strategies (that actually are out of the scope of the present work) to optimize the plasmid design, such as promoter, minicircles, or CpG free plasmids, should be considered to enhance the persistence of the gene expression. ${ }^{3}$

Another concern to be considered in the design of novel nonviral vectors based on cationic lipids is the toxicity of the formulation. One of the most widely employed commercial liposome reagents for in vitro transfection studies is Lipofectamine 2000. However, both in vivo subretinal and intravitreal injections of lipofectamine induce high toxicity in different layers of the retina even at low concentrations. ${ }^{17}$ Therefore, although lipofection technology remains widely popular for in vitro applications, tissue toxicity at the retina represents an important handicap that prevents its use in clinical trials. The in vivo OCT study can enhance visualization of morphologic features and could be used to evaluate the integrity of retina. SDOCT shows a cross-section of the retina, which appears as a histological slice perpendicular to the fundus and allows us to detect retinal pathologies or anomalous structures. In our SDOCT study, retinal morphologies were normal without any sign of toxicity associated with the formulations on high-resolution spectral OCT scans after one month post subretinal or intravitreous administration (see Supporting Information, Figure 2).

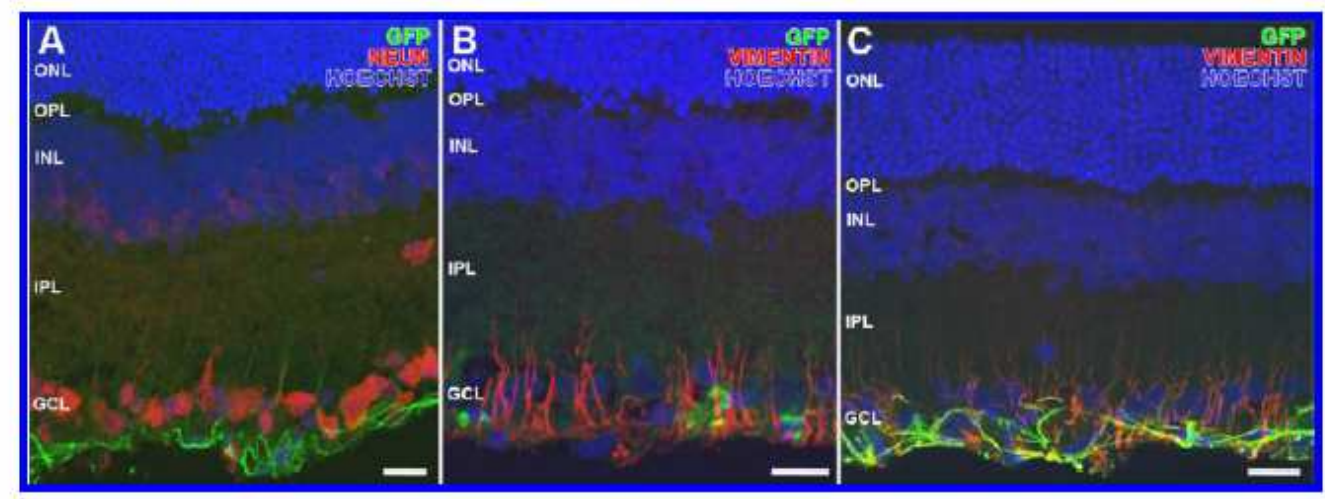

Figure 7. Immunohistochemical analysis of EGFP expression in retinal frozen sections 1 month after subretinal and intravitreal administration of protamine/DNA/niosome ternary vectors at 1:1:5 mass ratio. Double labeling on the $(A, B)$ subretinal and $(C)$ intravitreal injection. Retinal sections were performed with GFP (green) and NeuN or vimentin (red). (A,B) GFP immunofluorescent staining of retinal sections was predominantly in ganglion cell layer and nerve fiber layer and $(C)$ partial colocalization with the Müller glia cell marker vimentin. Cell nuclei were counterstaining with Hoechst 33342 (pseudocolored in blue). ONL, outer nuclear layer; OPL, outer plexiform layer; INL, inner nuclear layer; IPL, inner plexiform layer; GCL, ganglion cell layer. Scale bar $=20 \mu \mathrm{m}$.

\section{CONCLUSIONS.}

This work describes a novel nonviral formulation for efficient gene delivery to the retina. Protamine/DNA/niosome ternary vectors at 1:1:5 mass ratio were physicochemically characterized in terms of particle size, morphology, superficial charge, and capacity to condense, protect, and release the DNA. In vitro transfection experiments were performed in ARPE-19 cells. Interestingly, the incorporation of protamine to the niosome/ DNA formulation reduced the proportion of cationic lipid to transfect efficiently ARPE-19 cells, which resulted in a less toxic formulation when compared with their counterparts niosome/ DNA vectors. Moreover, the addition of protamine promoted DNA delivery into the nucleus, which is 
especially relevant in cells with low division rate such as retinal cells. After 1 month of ocular administration of ternary vectors, EGFP expression was detected in different cell layers of the retina depending on the administration route without any sign of toxicity associated with the formulations. While subretinal administration transfected mainly photoreceptors and retinal pigment epithelial cells at the site of injection, intravitreal administration produced a more uniform distribution of the protein expression through the inner layers of the retina. Our study highlights the flattering properties of protamine/DNA/niosome ternary vectors for efficient and safe gene delivery to the rat retina.

\section{ACKNOWLEDGMENTS}

This project was partially supported by the University of the Basque Country UPV/EHU (UFI 11/32), by the Research Chair in Retinosis Pigmentosas "Bidons Egara", the National Council of Science and Technology (CONACYT), Mexico, Reg. No. 217101, the Spanish Ministry of Education (Grant Nos. CTQ2010-20541, CTQ2010-14897), the Basque Government (Department of Education, University and Research, predoctoral BFI-2011-2226 grant), and by Spanish Grant Nos. MAT2012-39290-C02-01 and IPT-2012-0574-300000. Technical and human support provided by SGIker (UPV/EHU) is gratefully acknowledged. The authors also wish to thank the intellectual and technical assistance from the ICTS "NANBIOSIS", more specifically by the Drug Formulation Unit (U10) of the CIBER in Bioengineering, Biomaterials, and Nanomedicine (CIBER-BBN) at the University of Basque Country (UPV/ EHU).

\section{ABBREVIATONS}

DLS, dynamic light scattering; LDV, laser Doppler velocimetry; RPE, retinal pigment epithelial cells; FITC, fluorescein isothiocyanate; EMA, ethidium monoazide; TEM, transmission electron microscopy; SDS, sodium dodecyl sulfate; D-MEM/F- 12, Dulbecco's Modified Eagle's medium-Hanks Nutrient Mixture F-12; EGFP, enhanced green fluorescent protein; OCT, optical coherence tomography; PBS, phosphate buffer solution; GCL, ganglion cell layer; SLN, solid lipid nanoparticles; OC, open circular form; SC, supercoiled form; MFI, mean fluorescent intensity; 7-AAD, 7-aminoactinomycin D; OPL, outer plexiform layer; INL, inner nuclear layer; IPL, inner plexiform layer

\section{REFERENCES}

(1) Gardlik, R.; Palffy, R.; Hodosy, J.; Lukacs, J.; Turna, J.; Celec, P. Vectors and delivery systems in gene therapy. Med. Sci. Monit. 2005,11 (4), RA110-121.

(2) Choi, S.; Lee, K. D. Enhanced gene delivery using disulfidecrosslinked low molecular weight polyethylenimine with listeriolysin opolyethylenimine disulfide conjugate. J. Controlled Release 2008, 131 (1), 70-76.

(3) Adijanto, J.; Naash, M. I. Nanoparticle-based technologies for retinal gene therapy. Eur. J. Pharm. Biopharm. 2015, DOI: 10.1016/j.ejpb.2014.12.028.

(4) Bloquel, C.; Bourges, J. L.; Touchard, E.; Berdugo, M.; BenEzra, D.; Behar-Cohen, F. Non-viral ocular gene therapy: potential ocular therapeutic avenues. Adv. Drug Delivery Rev. 2006, 58 (11), 1224- 1242.

(5) Liu, M. M.; Tuo, J.; Chan, C. C. Gene therapy for ocular diseases. Br. J. Ophthalmol. 2011, 95

(5), 604-612.

(6) Lipinski, D. M.; Thake, M.; MacLaren, R. E. Clinical applications of retinal gene therapy. Prog. Retinal Eye Res. 2013, 32, 22-47.

(7) Issa, P. C.; MacLaren, R. E. Non-viral retinal gene therapy: a review. Clin Experiment Ophthalmol. 2012, 40 (1), 39-47.

(8) Verma, I. M. A tumultuous year for gene therapy. Mol. Ther. 2000, 2 (5), 415-416.

(9) Check, E. A tragic setback. Nature 2002, 420 (6912), 116-118.

(10) Smaglik, P. Merck blocks 'safer' gene therapy trials. Nature 2000, 403 (6772), 817. 
(11) Willard, H. F. Genomics and gene therapy. Artificial chromosomes coming to life. Science 2000, 290 (5495), 1308-1309.

(12) Harrington, J. J.; Van Bokkelen, G.; Mays, R. W.; Gustashaw, K.; Willard, H. F. Formation of de novo centromeres and construction of first-generation human artificial microchromosomes. Nat. Genet. 1997, 15 (4), 345-355.

(13) Schmidt-Wolf, G. D.; Schmidt-Wolf, I. G. Non-viral and hybrid vectors in human gene therapy: an update. Trends Mol. Med. 2003, 9 (2), 67-72.

(14) Kawakami, S.; Harada, A.; Sakanaka, K.; et al. In vivo gene transfection via intravitreal injection of cationic liposome/plasmid DNA complexes in rabbits. Int. J. Pharm. 2004, 278 (2), 255-262.

(15) Zhang, Y.; Schlachetzki, F.; Li, J. Y.; Boado, R. J.; Pardridge, W. M. Organ-specific gene expression in the rhesus monkey eye following intravenous non-viral gene transfer. Mol. Vis. 2003, 9, 465-472.

(16) Peeters, L.; Sanders, N. N.; Demeester, J.; De Smedt, S. C. Challenges in non-viral ocular gene transfer. Biochem. Soc. Trans. 2007, 35, 47-49.

(17) Kachi, S.; Oshima, Y.; Esumi, N.; et al. Nonviral ocular gene transfer. Gene Ther. 2005, 12 (10), 843-851.

(18) Puras, G.; Mashal, M.; Zarate, J.; et al. A novel cationic noisome formulation for gene delivery to the retina. J. Controlled Release 2014, 174, 27-36.

(19) Duvshani-Eshet, M.; Keren, H.; Oz, S.; Radzishevsky, I. S.; Mor, A.; Machluf, M. Effect of peptides bearing nuclear localization signals on therapeutic ultrasound mediated gene delivery. J. Gene Med. 2008, 10 (10), 1150-1159.

(20) Delgado, D.; Del Pozo-Rodriguez, A.; Solinis, M. A.; Rodriguez- Gascon, A. Understanding the mechanism of protamine in solid lipid nanoparticle-based lipofection: The importance of the entry pathway. Eur. J. Pharm. Biopharm. 2011, 79 (3), 495-502.

(21) Liu, J.; Guo, S.; Li, Z.; Liu, L.; Gu, J. Synthesis and characterization of stearyl protamine and investigation of their complexes with DNA for gene delivery. Colloids Surf., B 2009, 73 (1), 36-41.

(22) Li, S.; Huang, L. In vivo gene transfer via intravenous administration of cationic lipidprotamine-DNA (LPD) complexes. Gene Ther. 1997, 4 (9), 891-900.

(23) Li, S.; Rizzo, M. A.; Bhattacharya, S.; Huang, L. Characterization of cationic lipid-protamineDNA (LPD) complexes for intravenous gene delivery. Gene Ther. 1998, 5 (7), 930-937.

(24) Vighi, E.; Montanari, M.; Ruozi, B.; lannuccelli, V.; Leo, E. The role of protamine amount in the transfection performance of cationic SLN designed as a gene nanocarrier. Drug Delivery 2012, 19 (1), 1-10.

(25) Ruiz de Garibay, A. P.; Solinis Aspiazu, M. A.; Rodriguez Gascon, A.; Ganjian, H.; Fuchs, R. Role of endocytic uptake in transfection efficiency of solid lipid nanoparticles-based nonviral vectors. J. Gene Med. 2013, 15 (11-12), 427-440.

(26) Torrecilla, J.; del Pozo-Rodriguez, A.; Apaolaza, P. S.; Solinis, M. A.; Rodriguez-Gascon, A. Solid lipid nanoparticles as non-viral vector for the treatment of chronic hepatitis $C$ by RNA interference. Int. J. Pharm. 2015, 479 (1), 181-188.

(27) Kokotos, G.; Verger, R.; Chiou, A. Synthesis of 2-Oxo amide triacylglycerol analogues and study of their inhibition effect on pancreatic and gastric lipases. Chem. - Eur. J. 2000, 6 (22), 4211-4217.

(28) Ojeda, E.; Puras, G.; Agirre, M.; et al. Niosomes based on synthetic cationic lipids for gene delivery: the influence of polar headgroups on the transfection efficiency in HEK-293, ARPE-19 and MSCD1 cells. Org. Biomol. Chem. 2015, 13 (4), 1068-1081.

(29) Ochoa, G. P.; Sesma, J. Z.; Diez, M. A.; et al. A novel formulation based on 2,3di(tetradecyloxy)propan-1-amine cationic lipid combined with polysorbate 80 for efficient gene delivery to the retina. Pharm. Res. 2014, 31 (7), 1665-1675.

(30) Midoux, P.; Monsigny, M. Efficient gene transfer by histidylated polylysine/pDNA complexes. Bioconjugate Chem. 1999, 10 (3), 406- 411. 
(31) del Pozo-Rodriguez, A.; Delgado, D.; Solinis, M. A.; Gascon, A. R.; Pedraz, J. L. Solid lipid nanoparticles: formulation factors affecting cell transfection capacity. Int. J. Pharm. 2007, 339 (1-2), 261-268.

(32) Ma, B.; Zhang, S.; Jiang, H.; Zhao, B.; Lv, H. Lipoplex morphologies and their influences on transfection efficiency in gene delivery. J. Controlled Release 2007, 123 (3), 184-194.

(33) Conner, S. D.; Schmid, S. L. Regulated portals of entry into the cell. Nature 2003, 422 (6927), 37-44.

(34) Mercer, J.; Helenius, A. Gulping rather than sipping: macropinocytosis as a way of virus entry. Curr. Opin. Microbiol. 2012, 15 (4), 490-499.

(35) Bivas-Benita, M.; Romeijn, S.; Junginger, H. E.; Borchard, G. PLGA-PEI nanoparticles for gene delivery to pulmonary epithelium. Eur. J. Pharm. Biopharm. 2004, 58 (1), 1-6.

(36) McClements, M. E.; MacLaren, R. E. Gene therapy for retinal disease. Transl Res. 2013, 161 (4), 241-254.

(37) Bejjani, R. A.; BenEzra, D.; Cohen, H.; et al. Nanoparticles for gene delivery to retinal pigment epithelial cells. Mol. Vis. 2005, 11, 124-132.

(38) del Pozo-Rodriguez, A.; Pujals, S.; Delgado, D.; et al. A prolinerich peptide improves cell transfection of solid lipid nanoparticle-based non-viral vectors. J. Controlled Release 2009, 133 (1), 52-59.

(39) Delgado, D.; del Pozo-Rodriguez, A.; Solinis, M. A.; et al. Dextran and protamine-based solid lipid nanoparticles as potential vectors for the treatment of X-linked juvenile retinoschisis. Hum. Gene Ther. 2012, 23 (4), 345-355.

(40) Nguyen, L. T.; Atobe, K.; Barichello, J. M.; Ishida, T.; Kiwada, H. Complex formation with plasmid DNA increases the cytotoxicity of cationic liposomes. Biol. Pharm. Bull. 2007, 30 (4), 751-757.

(41) Masuda, T.; Akita, H.; Harashima, H. Evaluation of nuclear transfer and transcription of plasmid DNA condensed with protamine by microinjection: the use of a nuclear transfer score. FEBS Lett. 2005, 579 (10), 2143-2148.

(42) Delgado, D.; Del Pozo-Rodriguez, A.; Solinis, M. A.; et al. Dextran and protamine-based solid lipid nanoparticles as potential vectors for the treatment of $X$ linked juvenile retinoschisis. Hum. Gene Ther. 2012, 23 (4), 345-55.

(43) Varkouhi, A. K.; Scholte, M.; Storm, G.; Haisma, H. J. Endosomal escape pathways for delivery of biologicals. J. Controlled Release 2011, 151 (3), 220-228.

(44) Puras, G.; Zarate, J.; Diaz-Tahoces, A.; Aviles-Trigueros, M.; Fernandez, E.; Pedraz, J. L. Oligochitosan polyplexes as carriers for retinal gene delivery. Eur. J. Pharm. Sci. 2013, 48 (1-2), 323-331.

(45) Lipinski, D. M.; Thake, M.; Maclaren, R. E. Clinical applications of retinal gene therapy. Prog. Retinal Eye Res. 2013, 32, 22-47.

(46) Conley, S. M.; Naash, M. I. Nanoparticles for retinal gene therapy. Prog. Retinal Eye Res. 2010, 29 (5), 376397.

(47) Bennett, J.; Ashtari, M.; Wellman, J.; et al. AAV2 gene therapy readministration in three adults with congenital blindness. Sci. Transl. Med. 2012, 4 (120), 120ra15.

(48) Andreollo, N. A.; Santos, E. F.; Araujo, M. R.; Lopes, L. R. Rat's age versus human's age: the what is the relationship? Arq Bras Cir Dig. 2012, 25 (1), 49-51. 


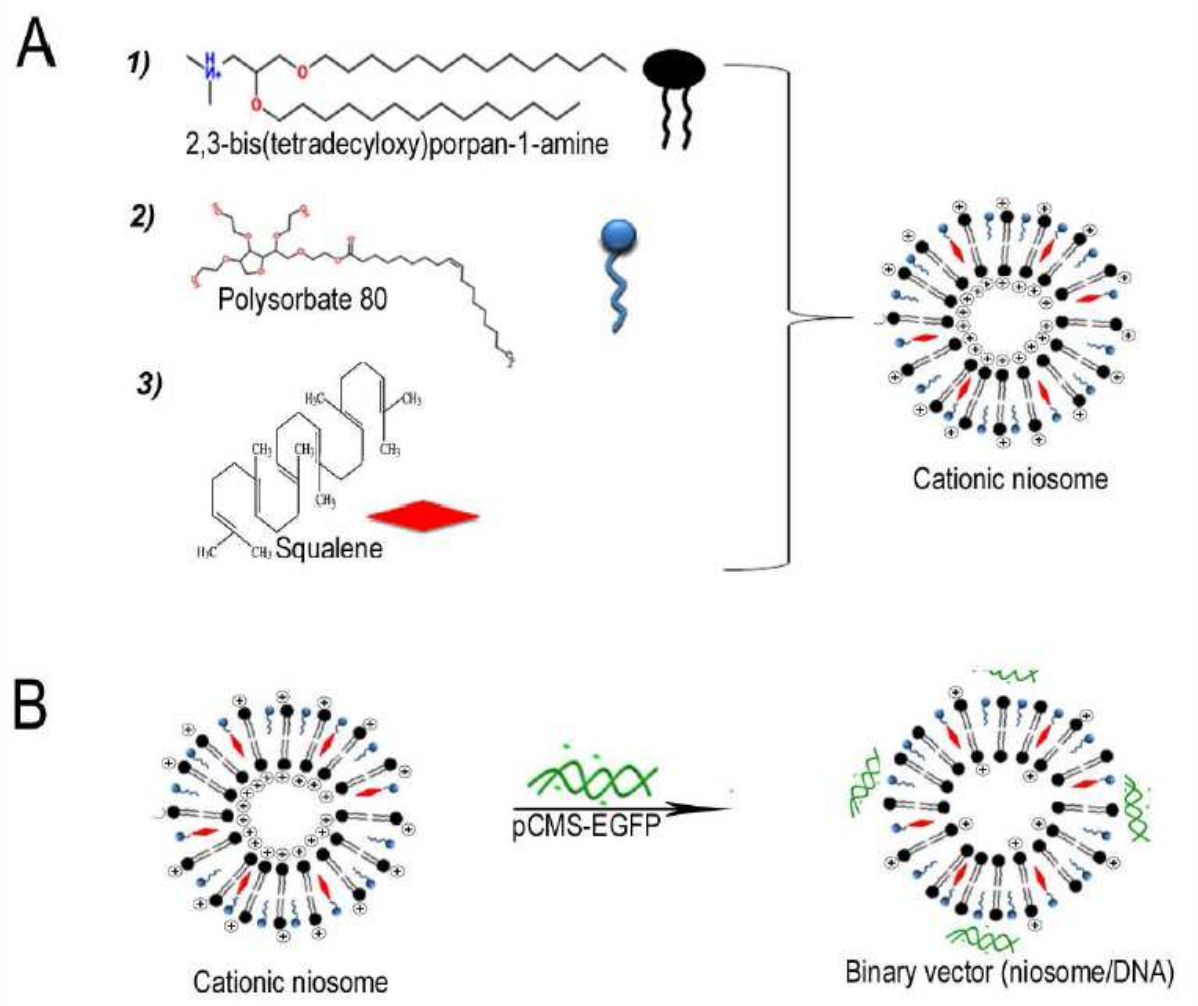

C

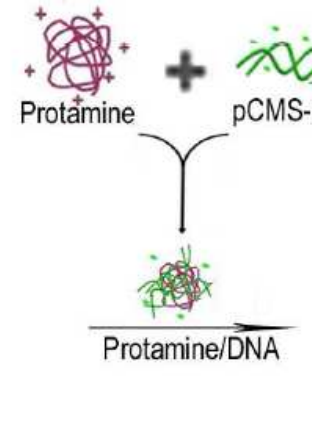

Cationic niosome

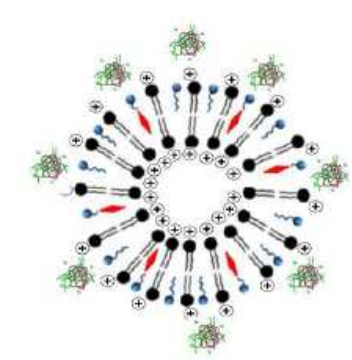

Ternary vector

(Protamine/DNA/niosome)

Supplementary data

Fig.1. A) Chemical compounds and structure of niosomes. B) Schematic representation of niosome/DNA binary vectors. C) Schematic representation of Protamine/DNA/niosome ternary vectors 

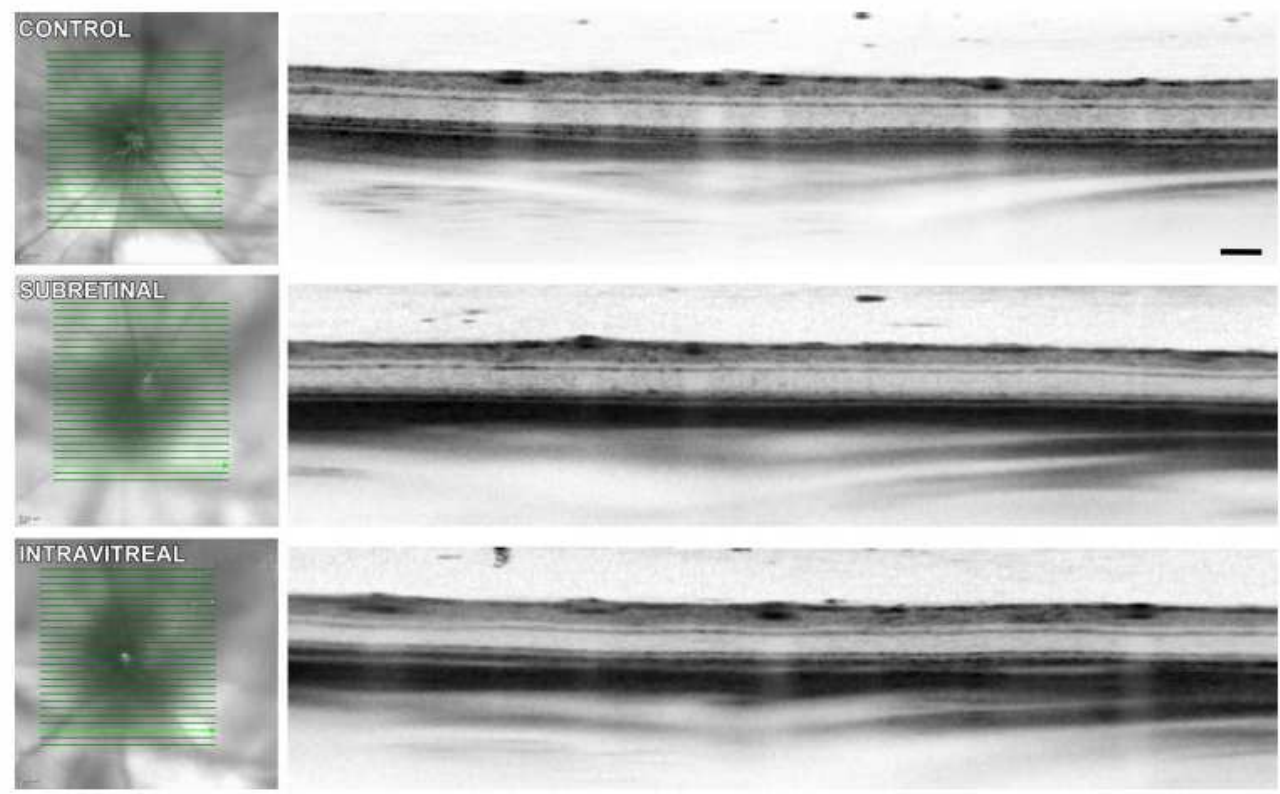

\section{Supplementary data}

Fig. 2. In vivo retinal imaging by spectral domain optical coherence tomography (SD-OCT) scan. Representative OCT examination reveals in control (without administration), subretinal and intravitreal administration normal retinal structure in the vertical cross-section after 1 month the administration. Scale bar $=100 \mu \mathrm{m}$. 